\title{
Testando as Hipóteses do Modelo de Mincer para o Brasil $^{*}$
}

\author{
Rodrigo Leandro de Moura ${ }^{\dagger}$
}

\footnotetext{
Conteúdo: 1. Introdução; 2 . Revisão de Literatura; 3. Equivalência entre a TIR e o coeficiente "minceriano"; 4. Testando as hipóteses de Mincer; 5. TIR; 6. Conclusão; A. Lista de Figuras e Tabelas.

Palavras-chave: Retorno da educação; seleção amostral; plano amostral; regressão linear local.

Códigos JEL: I20; J24; C14; C42.
}

Várias estimativas de taxas de retorno para educação têm sido produzidas, baseadas no modelo de Mincer. Mas algumas das hipóteses (linearidade e separabilidade), para que o coeficiente escolar ("minceriano") seja interpretado como taxa de retorno, são testadas e rejeitadas. Ao relaxar tais hipóteses, estimamos as taxas internas de retorno Becker (1975) e obtemos vieses que chegaram a 14 pontos percentuais em relação ao coeficiente "minceriano". Assim, a magnitude destes retornos é bem menor do que os estudos baseados no modelo de Mincer. Nas estimações incorporamos o desenho amostral da PNAD e corrigimos o problema do viés de seleção amostral.

Many estimates of rates of return for education have been produced, based on the Mincer's model. But some of the hyphoteses (linearity and separability), so that the ("mincer") school coefficient is interpreted as rate of return, are tested and rejected. When relaxing such hypotheses, we estimate the internal rates of return Becker (1975) and we get biases that arrive to 14 percentile points in relation to the "mincer coefficient". Thus, the magnitude of these returns is much lower than the papers based on Mincer's model. In the estimates we incorporate the sample design of PNAD and correct the problem of bias of sample selection.

\footnotetext{
*Agradeço ao Carlos Eugênio da Costa, da EPGE/FGV, pelos diversos comentários e orientação na elaboração deste artigo; a Petra Todd, da University of Pennsylvania, pelos códigos em R cedidos que foram importantes na realização de alguns testes neste artigo; ao Luis Henrique Braido, Luis Renato Lima, da EPGE/FGV, e a todos os participantes do Seminário de Almoço da EPGE por suas diversas sugestões e críticas; ao Breno Néri, doutorando da New York University, por seu auxílio em uma rotina; a Elaine Toldo Pazello, da FEA-RP/USP, por suas sugestões; ao Maurício Lila, Djalma Pessoa e Pedro Nascimento Silva, do IBGE, por seus auxílios em relação à PNAD e Censo; agradeço a todos os participantes do XXVIII Encontro Brasileiro de Econometria (SBE), quando da apresentação de uma versão preliminar deste artigo; e por fim agradeço os comentários de um parecerista anônimo. Os erros remanescentes são de inteira responsabilidade do autor.

† Doutor em Economia pela EPGE/FGV-RJ. Professor da Graduação em Economia da FGV-RJ
} 


\section{INTRODUÇÃO}

A decisão de acumulação de capital humano (educação, treinamento no emprego, saúde etc) passa pela mensuração correta de seus retornos. Uma forma de medi-los é através da taxa interna de retorno (TIR), um conceito central da teoria do capital humano, desenvolvido na análise desta decisão dos investimentos dos agentes em capital humano. Esta medida remonta a Becker (1975) (daqui em diante Becker) e Schultz (1963). Assim, o agente investe em capital humano através da comparação dos fluxos de benefícios e custos, do qual se extrai a taxa de desconto que os igualam. Logo, um agente neutro ao risco, que maximiza a sua riqueza, tende a concentrar seus investimentos em idades precoces, pois: (i) com o passar do tempo o indivíduo tem um menor período para retomar o retorno do investimento em capital humano e (ii) o custo de oportunidade vai se elevando com o maior nível de capital humano. Aqui nos atemos a um componente do capital humano que seria a educação. Pessoas mais educadas tendem a obter maiores rendimentos. Essa lógica se aplica, pois com uma maior acumulação de educação tendem a melhorar suas habilidades, conhecimento e saúde, as quais aumentam a produtividade do trabalho. E esta última iguala os rendimentos em um mercado perfeitamente competitivo. ${ }^{1}$ Assim, a mensuração correta da TIR depende da estimação do perfil de rendimentos dos indivíduos ao longo do seu ciclo de vida.

No entanto, na literatura empírica, várias estimativas de taxas de retorno têm sido reportadas, baseadas nos modelos seminais de Mincer $(1958,1974)$, (daqui em diante Mincer I e Mincer II respectivamente), que derivam a equação de salários:

$$
\ln Y(s, x)=\alpha+\beta s+\gamma x+\delta x^{2},
$$

em que, $Y(s, x)$ é a renda ajustada pelas horas de trabalho, $s$ é anos de estudo e $x$ é a experiência. O coeficiente $\beta$ é conhecido como coeficiente (ou retorno) minceriano de educação. Heckman (2005) aponta que, nos EUA, existem alguns aparentes puzzles empíricos, tais como: os altos retornos "mincerianos" da educação vis a vis outros investimentos; e dado isto, observa-se uma resposta lenta de matrículas das coortes recentes. Mas segundo Heckman et alii (2006) ${ }^{2}$ (daqui em diante HLT), poucas destas estimativas são taxas de retorno verdadeiras. Muitas das hipóteses do modelo de Mincer, que tornariam o coeficiente minceriano uma taxa de retorno (TIR), são válidas sob circunstâncias muito restritas. Assim, o estudo de retornos educacionais passa, invariavelmente, pelos modelos originais de Mincer, em que suas hipóteses devem ser testadas.

No Brasil diversos estudos consideram o coeficiente minceriano como taxa de retorno, mas nenhum tem realizado qualquer tipo de teste. No entanto, diversos estudos já realizaram testes de linearidade Hungerford e Solon (1987), Jaeger e Page (1996), Heckman et alii (1996a) e recentemente paralelismo (HLT) para os EUA, rejeitando tais hipóteses, cruciais para esta interpretação do coeficiente ser um retorno educacional.

Assim, as TIR's podem ser entendidas como o custo de oportunidade de se investir em educação, em relação a outras alternativas. E, ao contrário do retorno "minceriano", a TIR considera os custos (diretos e indiretos). Portanto, somente no caso das hipóteses do modelo de Mincer serem satisfeitas e sob algumas restrições adicionais, podemos afirmar que a TIR é igual ao coeficiente minceriano. Algumas destas hipóteses são: o tempo da vida do trabalho seja igual para todos os indivíduos independentemente do nível educacional; durante a escolarização os agentes não trabalhem; os únicos custos incorridos sejam os custos de oportunidade, ou seja, os rendimentos sacrificados advindos do mercado de trabalho durante o período de escolarização; não exista incerteza; agentes neutros ao risco; não existam imperfeições no mercado de crédito; linearidade nos anos de estudo e separabilidade entre experiência e anos de estudo (paralelismo). Assim, a partir de dados semelhantes e a mesma estrutura do modelo de Mincer, testamos

\footnotetext{
${ }^{1}$ Obviamente existem outros beneficios (não-monetários) derivados desse processo de aprendizagem, mas, segundo Becker, resultados apontam para uma menor importância destes outros beneficios.

${ }^{2}$ Uma versão anterior deste trabalho foi circulada sob o título Fifty Years of Mincer Earnings Regressions.
} 
para as duas últimas hipóteses citadas e rejeitamos ambas. Portanto, neste caso, o retorno minceriano seria melhor entendido como uma taxa de crescimento dos salários de mercado devido ao acréscimo marginal nos anos de estudos, ou ainda, como o preço marginal da educação.

Em seguida calculamos as TIRs, tendo como referência os coeficientes mincerianos, e mostramos que o viés é relativamente alto quando relaxamos as hipóteses de linearidade e paralelismo. Obtemos vieses que chegaram a um pouco mais de 14 pontos percentuais, ao comparar o retorno minceriano (17.29\%) com a TIR (3.03\%) para o Mestrado-Doutorado em relação ao Ensino Superior. Diversos estudos no Brasil não consideram tais hipóteses e, conseqüentemente, suas estimativas estão imprecisas e o grau desta discrepância é relativamente grande, podendo levar à conclusões distorcidas ou mal interpretadas. Adicionalmente, relaxamos também algumas das outras hipóteses citadas.

Utilizamos duas técnicas econométricas, a saber: regressão paramétrica e não-paramétrica. Os testes de linearidade envolvem a primeira, os testes de paralelismo envolvem a segunda, enquanto o cálculo das TIRs envolve ambos instrumentais. Em todas estimativas, lançamos mão das bases de dados da PNAD e do Censo. Em relação à PNAD, por se tratar de uma pesquisa amostral complexa, a hipótese de uma amostra aleatória independente e identicamente distribuída não pode ser assumida. Por isso, incorporamos o desenho (plano) amostral da PNAD ${ }^{3}$ que pode ser considerado um ganho adicional na literatura empírica para o Brasil. ${ }^{4}$ Além disso, corrigimos também para o problema de viés de seleção amostral que surge devido ao fato de que alguns indivíduos escolhem não trabalhar pois o salário de mercado é fixado abaixo do seu salário de reserva. Esta correção também pode ser considerada um ganho adicional, visto que mesmo estudos recentes, como HLT, não incorporaram tal aspecto, o que altera a magnitude das TIRs. Assim, comparamos estimativas feitas sem correção, incorporando o desenho amostral, e estimando por heckit. ${ }^{5}$

$\mathrm{O}$ artigo segue a seguinte estrutura: seção 2 realiza uma revisão seletiva da literatura; seção 3 mostra através de um modelo simples a equivalência entre a TIR e o coeficiente minceriano; seção 4 apresenta a metodologia e os resultados dos testes de linearidade e paralelismo; seção 5 mostra a metodologia, resultados e discussão das TIRs; e seção 6 conclução.

\section{REVISÃO DE LITERATURA}

A revisão seletiva da literatura apresenta as evidências internacionais e nacionais em relação aos artigos que aplicam os modelos de Mincer e o conceito da TIR.

\subsection{Evidência Internacional - Mincer}

Em uma resenha recente, Card (1999) aponta que estudos que relacionam educação a rendimentos se baseiam quase sempre e fortemente nos modelos de Mincer. A forma funcional de Mincer tem levantando várias objeções. Card já apontava que uma forma dos rendimentos serem estimados poderia ser através de técnicas não paramétricas, como uma função geral de anos de estudo e idade. Já na linha de estimação paramétrica, Murphy e Welch (1990) mostram que um termo linear nos anos de estudo e um polinômio até de ordem três ou quatro na experiência provê uma melhora significativa no ajuste. Um fato importante destacado por estes dois estudos é que este modelo paramétrico tem problemas em ajustar o formato preciso dos perfis de rendimento-idade (experiência) para os dados americanos, pois tende a viesar a taxa de crescimento estimada dos rendimentos dos trabalhadores com determinado

\footnotetext{
${ }^{3}$ Este ponto será discutido mais detalhadamente na seção 4.2 .

${ }^{4}$ Em relação ao Censo, a incorporação do desenho amostral não foi possível. As variáveis que permitiram a incorporação do desenho amostral do Censo são consideradas "dados sigilosos"pelo IBGE e por isso não podem ser divulgadas.

${ }^{5} \mathrm{~A}$ correção do viés de seleção amostral foi feita apenas para os modelos paramétricos. Para os modelos não-paramétricos não foi possível devido à grande complexidade e extensão do procedimento. Tal ajuste foi proposto por Das et alii (2003), o qual poderá ser incorporado em pesquisa futura.
} 
nível escolar, em relação ao valor amostral. Isso ocorre devido à má especificação do modelo. Outro problema que surge destes modelos é a redução da parcimônia ao se adicionar termos cúbico e quártico à especificação, levando a um problema de multicolinearidade maior nas estimativas. Estes problemas podem ser contornados pela estimação não paramétrica.

No entanto, Card destaca o alto poder explicativo do modelo minceriano. Segundo Park (1994), para os EUA, o termo linear na educação ajusta-se bem aos dados. Mas existem evidências contrárias ao modelo linear apontado por Hungerford e Solon (1987), Belman e Heywood (1991), Jaeger e Page (1996) e Heckman et alii (1996b), que estimam o modelo minceriano adicionado de componentes de não linearidade, como por exemplo, dummies para os anos de conclusão do curso para captar efeitos diploma. ${ }^{6}$ Um teste F executado sobre estes termos não lineares rejeita fortemente o modelo linear.

Psacharopoulos e Patrinos (2004), Psacharopoulos (1994, 1985) revisa as estimativas da taxa de retorno baseadas no modelo minceriano, para diversos países, obtendo prêmios por educação maiores para América Latina/Caribe e África Subsaariana - países de baixa e média renda - que estão acima do retorno médio mundial. Além disso, nos últimos doze anos, os retornos mincerianos médios mundiais tem decaído $0.6 \%$, enquanto o nível médio de escolarização aumentou. ${ }^{7}$

\subsection{Evidência Brasileira - Mincer}

Em relação ao Brasil, diversos estudos consideram e estimam o coeficiente minceriano como taxa de retorno. A maioria relaxa a hipótese de linearidade, estimando uma função spline nos anos de estudo, como em Leal e Werlang (1991). Blom e Verner (2001) é um estudo recente que atualiza os retornos mincerianos para o Brasil, utilizando o modelo de Mincer II, mas relaxando a linearidade ao utilizar uma função spline com nós nos anos de conclusão dos ciclos. Os autores, utilizando regressões de média e quantílicas condicionais, observam que o spread dos retornos entre os diferentes quantis é grande para todos os níveis, com exceção do terciário. Eles sugerem que esta dispersão grande poderia ser devido a fatores não controlados (qualidade da escola, capital social e habilidade não observada) relacionados aos retornos e que o seu modelo estimado deveria permitir interação entre educação e outros termos como experiência, o que relaxaria de uma forma a hipótese de paralelismo.

Sachsida, Sachsida et alii (2004), utilizando a PNAD de 1996 e diversos anos empilhados (1992-99), calculam o retorno minceriano segundo Mincer II, mas corrigindo para algumas fontes de vieses, tais como: seleção amostral, endogeneidade da variável educação e habilidade do indivíduo não observada. Soares e Gonzaga (1999), usando a PNAD de 1988, testam a existência de dualidade no mercado de trabalho brasileiro, no sentido da existência de estruturas salariais distintas associadas a ocupações boas (ligadas, por exemplo, a maiores retornos educacionais, dentre outros fatores) e a ocupações ruins. Estes dois estudos e o de Loureiro e Carneiro (2001) são um dos poucos que relaxam a hipótese de linearidade e paralelismo, mas impondo uma forma funcional à sua equação. Os resultados destes estudos apontam para significância do termo de interação de tempo de trabalho e anos de estudo e, assim, rejeitando a hipótese de paralelismo.

Outros estudos, que não tem o objetivo principal estimar taxas de retorno, utilizam o modelo de Mincer em suas análises. Fernandes e Filho (2000) avaliam a evolução da desigualdade dos rendimentos do trabalho, utilizando uma regressão minceriana (Mincer II) adicionada de alguns controles, e relaxando a hipótese de linearidade nos anos de estudo. O retorno educacional minceriano, em seu estudo, é um

\footnotetext{
${ }^{6}$ Efeitos diploma (sheepskin effects) captam os efeitos dos retornos maiores devido à obtenção de algum grau escolar. Este "diploma"pode ser interpretado como um sinal da produtividade para que o mercado contrate o trabalhador.

${ }^{7}$ O período de referência depende do país, variando de 1970 em Marrocos até 1998 em Cingapura e Filipinas. Algumas destas estimativas foram obtidas pelo autor através de outros artigos. Psacharopoulos e Patrinos (2004) aponta que estas comparações não são exatas, devido a diferenças na metodologia e na cobertura amostral.
} 
fator explicativo importante na redução da desigualdade, principalmente entre 1990 e $1991 .^{8}$

\subsection{Evidência Internacional - TIR}

Voltando-se especificamente para a TIR, Becker dirime uma questão importante na relação rendimentoscustos-taxas de retorno: a dificuldade de isolar o efeito nos rendimentos derivado de uma mudança dos retornos ou de uma mudança da soma investida em educação. No contexto de um modelo estático, em que investimento é restrito a somente um único período e retornos a todos os períodos remanescentes, Becker afirma que custo e taxa de retorno são facilmente determinados tomando apenas os rendimentos líquidos. Para isso, comparam-se os fluxos de rendimentos de dois níveis de ensino, um com investimento no primeiro período e o outro que não requer soma dispendida. O custo de se investir em educação seria os rendimentos sacrificados líquidos de se investir. Este é o contexto do nosso modelo de estimação da TIR. ${ }^{9}$

Schultz (1963) já apontava também que os custos deveriam ser levados em consideração na análise de investimentos em educação. Estes custos se estendem além das despesas com mensalidades, anuidades e outras, onde os salários sacrificados compõem parte significativa dos custos. No contexto da economia como um todo, custos executados pelas escolas (manutenção da infra-estrutura, depreciação e serviços) são de relevância, enquanto num contexto de decisão individual, os custos diretos e indiretos dos estudantes são os mais importantes. Destes últimos, o custo do tempo do estudante na escola é destacado por Schultz, sendo estes estimados dos salários que os estudantes deixam de receber enquanto do período de escolarização. Como não existe um contrafactual perfeito, do qual extrairíamos o fluxo de renda para o caso do indivíduo freqüentar e não freqüentar escola, temos de tomar como referência agentes com características similares, mas que estejam no mercado de trabalho.

Psacharopoulos e Patrinos (2004) também estima a TIR, privada e social, para diversos países, e destaca que a América Latina/Caribe e a África Subsaariana são as regiões com maior retorno, para todos os níveis educacionais. Psacharopoulos (1994) destaca que o método da TIR é o mais apropriado, mas afirma que esta metodologia tem sido preterida em relação à Mincer II devido à falta de uma base com um número grande de observações em uma dada célula do nível educacional-idade para construir perfis de rendimentos-idade bem comportados (sem cruzamento e côncavo). Mas esse argumento têm se tornado fraco, dada a gama de bases existente atualmente.

\footnotetext{
${ }^{8}$ Dada a enorme gama de estudos sobre retorno educacional, baseados no modelo minceriano, não foi possível descrevê-los em detalhes. Mas vale citar outros estudos recentes que utilizam o modelo de Mincer tais como:

(i) Resende e Wyllie (2006) e Loureiro e Carneiro (2001) corrigem para o problema do viés de seleção amostral utilizando uma funçã o linear da educação, sendo que o primeiro controla para qualidade da educação utilizando a PPV entre 1996 e 1997 e o segundo utilizando a PNAD de 1998 conclui que existem diferenciais de salários entre os trabalhadores rurais e urbanos e discriminação por raça e gênero.
}

(ii) Ueda (2002) estimam o retorno educacional por mínimos quadrados e variáveis instrumentais, utilizando especificações linear e não-linear e incluindo variáveis sócio-econômicas. Utilizam a PNAD de 1996.

(iii) de Deus Vieira Silva e Kassouf (2000) avaliam o grau de segmentação do mercado de trabalho, corrigindo também para o problema de seleção amostral, mas utilizando um modelo logit multinomial na estimação da equação de seleção, a fim de diferenciar os não-ocupados e os ocupados do setor formal e informal. Utilizam a PNAD de 1995.

${ }^{9}$ Pesquisa futura pode incluir uma análise dinâmica. O problema aqui é a falta de base de dados no Brasil que siga o indivíduo por toda sua vida escolar e por, pelo menos, uma parte de sua vida profissional e que assim fosse possível mensurar estas decisões de investimento do agente. 


\subsection{Evidência Brasileira - TIR}

Em relação ao Brasil, Langoni (1974) foi um dos pioneiros a estimar a TIR para o país, baseado em Schultz (1963) e Becker. Ele calculou os custos diretos (despesas com infra-estrutura da escola e sua depreciação, salários dos professores e despesas por parte dos estudantes) e os indiretos (rendimentos que os estudantes deixam de ganhar por estarem fora do mercado de trabalho, e do capital da escola medidos pelos juros sacrificados pela instituição de ensino). Vale notar que o autor incluiu custos da escola, pois a medida de interesse é a taxa social de retorno, diferente da taxa privada de retorno que não inclui tais componentes. ${ }^{10}$ Para o cálculo da TIR é imprescindível a mensuração dos perfis de rendimentos por experiência (idade), e Langoni os mede através de médias amostrais e não através de regressões, ${ }^{11}$ utilizando dados em cross section. As TIR's variam entre 1960 e 1969 , de $48.1 \%$ para 32\% para o primário em relação aos analfabetos; de $23.8 \%$ para $19.5 \%$ para o ginásio em relação ao primário; de $14.8 \%$ para $21.3 \%$ para o colegial em relação ao ginásio; de $4.9 \%$ para $12.1 \%$ para o superior em relação ao colegial. Barbosa Filho e Pessoa (2008) atualizam o trabalho de Langoni utilizando a sua metodologia. A seguir mostramos a equivalência entre a TIR e o coeficiente "minceriano".

\section{EQUIVALÊNCIA ENTRE A TIR E O COEFICIENTE “MINCERIANO”}

Mincer I e Mincer II chegam ao mesmo modelo, mas sob motivações diferentes. ${ }^{12}$ Mincer I usa o princípio de diferenciais compensatórios para explicar porque agentes com níveis diferentes de educação recebem rendimentos diferentes ao longo de seus ciclos de vidas. Já Mincer II assume que os agentes podem investir em capital humano após a escola (treinamento no emprego) a fim de adquirir e aprimorar suas habilidades (skills), ampliar seu conjunto de informações sobre sua ocupação e aumentar seus rendimentos potenciais. Mincer II obtém exatamente a equação 1, enquanto Mincer I apresenta a mesma forma funcional, mas sem os termos de experiência.

Portanto, nesta seção mostramos que, sob determinadas hipóteses, o coeficiente minceriano $\beta$ da equação 1 seja igual a TIR para educação. Seja $Y(x, s)$ os rendimentos anuais de um indivíduo com $x$ anos de trabalho e $s$ anos de educação, e $l$ o tempo total de trabalho. As hipóteses diretas e indiretas assumidas no modelo de Mincer para se mostrar essa equivalência ${ }^{13}$ são: (i) um agente neutro ao risco que maximize o valor presente da renda esperada ao longo do ciclo de vida, (ii) que $l^{\prime}(s)=1$ (ou seja, que o tempo de trabalho seja igual para todos indivíduos independentemente do nível educacional), (iii) que os únicos custos incorridos sejam o custo de oportunidade, ou seja, os rendimentos protelados advindos do mercado de trabalho durante o período de escolarização, (iv) que não exista incerteza, (v) que os agentes entrem no mercado de trabalho um período após o encerramento dos estudos, (vi) que durante a escolarização eles não trabalhem, (vii) que não exista imperfeições no mercado de crédito, (viii) que após a obtenção de um emprego, os agentes não retornam à educação, que a forma funcional dos rendimentos seja (ix) (em log) linear sobre a educação e (x) (em nível) separável multiplicativamente entre educação e experiência. Esta última hipótese não permite uma interação entre educação e experiência e pode ser melhor visualizada reescrevendo a equação 1 e obtendo a seguinte função de produção de

\footnotetext{
${ }^{10}$ Langoni aparentemente não incorpora os impostos do lado dos beneficios, o qual seria mais correto na estimação de uma taxa social de retorno.

${ }^{11} \mathrm{O}$ problema da média amostral é que ela é menos eficiente, em termos de menor variância, do que o estimador de mínimos quadrados ordinários. Assim, o gráfico do perfil de rendimentos-experiência (idade), por nível educacional, pelas regressões tende a ser extremamente suavizada, enquanto da média amostral não apresenta nenhuma suavização, podendo apresentar relações espúrias das variáveis. Contornamos este problema, utilizando regressões não paramétricas que não impõe uma forma funcional e controlamos o parâmetro de suavização do perfil de rendimentos. Vale ressaltar também que regredir uma variável contra outras impõe um relação de casualidade entre a endógena e as exógenas, enquanto a média amostra não.

${ }^{12} \mathrm{~A}$ revisão destes modelos seminais encontra-se na versão longa deste artigo que pode ser requisitada ao autor.

${ }^{13}$ Esta equivalência é mostrada também em HLT e Willis (1986), que derivam para o caso do tempo contínuo.
} 
capital humano:

$$
Y(x, s)=\lambda(s) \theta(x),
$$

em que, $\lambda(s)=\lambda(0) e^{\beta s}$, e $\theta(x)=e^{\gamma x+\delta x^{2}}$. Assim, temos que $\frac{\partial \ln Y(x, s)}{\partial s \partial x}=0$, ou seja, os rendimentos em log são paralelos na experiência entre os diversos graus de educação (hipótese de paralelismo).

Willis (1986) aponta também uma hipótese adicional da economia como um todo: que a economia e a população estão no equilíbrio de estado estacionário de longo prazo, sem mudança da produtividade agregada e uma taxa constante do crescimento populacional, tal que o valor presente dos rendimentos do ciclo da vida é de um agente representativo. Assim, o agente maximiza o valor presente de seus rendimentos, escolhendo a quantidade discreta de anos de educação:

$$
\max _{\{s\}_{0}^{\bar{s}}} \sum_{x=0}^{l} \frac{Y(x, s)}{(1+r)^{s+x}} .
$$

Supondo paralelismo e linearidade nos anos de estudo, ou seja, $Y(x, s)=\lambda(0) e^{\beta s} \theta(x), \theta(x)<\infty$, teremos como condição de primeira ordem:

$$
\begin{aligned}
\sum_{x=0}^{l} \frac{Y(x, s+1)}{(1+r)^{1+x}}-\sum_{x=0}^{l} \frac{Y(x, s)}{(1+r)^{x}} & =0, \\
{\left[\frac{\lambda(0) e^{\beta(s+1)}}{1+r}-\lambda(0) e^{\beta s}\right] \sum_{x=0}^{l} \frac{\theta(x)}{(1+r)^{x}} } & =0 .
\end{aligned}
$$

Para $r \neq(-1,0)$ teremos:

$$
\begin{aligned}
\frac{\lambda(0) e^{\beta(s+1)}}{1+r}-\lambda(0) e^{\beta s} & =0, \\
e^{\beta s}-1 & =r .
\end{aligned}
$$

Assim, para valer a equivalência, as hipóteses principais assumidas são linearidade e paralelismo. Estas hipóteses serão testadas. Antecipando os resultados, veremos que elas são rejeitadas, motivando assim seu relaxamento, bem como adicionalmente as hipóteses (ii), (iii) e (vi).

\section{TESTANDO AS HIPÓTESES DE MINCER}

Na subseção a seguir discutimos algumas limitações de nossa abordagem ao utilizar dados em crosssection. Na subseção seguinte apresentamos os dados e algumas estatísticas preliminares. A seguir apresentamos a metodologia do teste de linearidade e os seus resultados e na última parte desta seção apresentamos a metodologia do teste de paralelismo e seus resultados.

\subsection{Discussão}

Assim, como apontado por HLT, a utilização de dados em cross-section nos leva a uma hipótese que pode ser relativamente forte: que os indivíduos se baseiam, numa análise ex-ante de suas decisões de investimento, no perfil de rendimento-experiência dos indivíduos mais velhos em idade de trabalho ativa. Esta é uma versão da hipótese de expectativas racionais na qual os agentes prevêem seus rendimentos baseado no perfil de rendimentos de indivíduos mais velhos Heckman (2005). Assim, não se leva em consideração que os agentes podem antecipar mudanças futuras no preço da educação, por exemplo. Deve-se ressaltar, no entanto, que o fato dos indivíduos basearem suas decisões de investimento em capital humano em indivíduos mais velhos é válido pois não existe um contrafactual perfeito, do qual 
poderia se extrair o fluxo de renda para o caso do indivíduo freqüentar e não freqüentar escola. Assim, temos de tomar como referência agentes com características similares.

Além disso, o uso de cross section, segundo Card (1999), é válido se ele refletir, mediante os diferenciais de rendimentos, diferenças de produtividade verdadeiras, e não devido a diferenças de habilidade inerentes ao indivíduo, que poderia estar correlacionada com a educação. Este problema de endogeneidade tem sido abordado intensamente na literatura; e no Brasil, recentemente, Sachsida et alii (2004) estimaram os retornos mincerianos, corrigindo para diversas fontes de vieses. Vale destacar que o viés ocasionado por habilidade e outros fatores omitidos não ultrapassa $10 \%$ do valor do coeficiente minceriano para os EUA Card (2001). Para o Brasil, Binelli e Filho (2006) mostram que este viés, originado da heterogeneidade não observada, é relativamente pequeno para os retornos relativos.

\subsection{Dados e Estatísticas Descritivas}

A PNAD por se tratar de uma pesquisa amostral "complexa"merece um cuidado especial. Portanto, discutimos brevemente a literatura que explica e incorpora o desenho (plano) amostral de uma pesquisa e adverte para as consequiências de sua não-consideração.

Desenho Amostral Os custos de se realizar uma pesquisa amostral baseada em um desenho amostral simples são muito altos. Por isso, segundo Chromy e Abeyasekara (2005), utilizam-se desenhos amostrais complexos para controlar tais custos. Segundo Yansaneh (2005), o desenho amostral complexo envolve estratificação, amostragem em multi-estágios (conglomeração ou cluster) e probabilidades de seleção diferentes. Em relação à conglomeração, a observação selecionada no primeiro estágio geralmente é denominada como unidade primária de amostragem (UPA). Estas UPAs podem ser divididas em áreas urbanas e rurais, ou ainda, em alguns países, seriam divididas em áreas geográficas ou administrativas. As observações selecionadas de cada UPA são denominadas unidades de segundo-estágio (USAs), e dentro destas as de terceiro estágio (UTAs), e assim sucessivamente. Geralmente as USAs são divididas como domicílios ou famílias e as UTAs seriam as pessoas. A estratificação é geralmente aplicada em cada estágio da amostragem, na qual particiona-se as unidades (de primeiro, segundo, terceiro estágios) em subgrupos mutuamente exclusivos. Estas unidades geralmente são selecionadas com probabilidades proporcionais ao seu tamanho (por exemplo, o número de famílias ou pessoas pertencentes a uma UPA) e, portanto, podendo ser desiguais em cada estágio. Assim, segundo Pessoa e Silva (1998) e IBGE (2004), o desenho amostral complexo da PNAD emprega uma amostra estratificada de domicílios em três estágios, tendo como UPAs os municípios, que são estratificados segundo as unidades da federação (UFs), e regiões menores dentro das UFs. A seleção de municípios dentro de cada estrato é feita com probabilidades desiguais, proporcionais ao tamanho, havendo inclusive municípios incluídos na amostra com probabilidade igual a um (chamados de municípios auto-representativos). As USAs são setores censitários e da mesma forma, a seleção destes setores dentro de cada município é feita com probabilidades proporcionais ao número de domicílios em cada setor segundo o último Censo disponível. No último estágio foram selecionados os domicílios em cada um destes setores, com igual probabilidade. Todas as pessoas moradoras em cada domicílio da amostra são pesquisadas.

No entanto, os estudos em geral não consideram para tais aspectos, partindo de hipóteses básicas que só seriam válidas quando os dados são obtidos através de amostras aleatórias simples com reposição ou, equivalentemente, independência e igualdade de distribuição (iid). Geralmente, dados obtidos de pesquisas por amostragem, como a PNAD, não permitem o uso de tais hipóteses Silva et alii (2002).

Diversos estudos em Economia não consideram o desenho amostral complexo ao estimar a variância, na construção de intervalos de confiança e de testes de hipóteses, gerando, segundo Lumley (2004), estimativas viesadas, o que, a rigor, acaba invalidando os testes de hipóteses usuais. Assim, seus resultados estão imprecisos, podendo acarretar em uma mudança apenas quantitativa ou até uma mudança qualitativa, ao alterar a (não-)significância dos parâmetros estimados. Portanto, este estudo visa também contribuir nessa questão, ao incorporar o desenho amostral da PNAD. 
Testando as Hipóteses do Modelo de Mincer para o Brasil

Amostra e Estatísticas Descritivas Portanto, em todos os testes realizados utilizaram-se dados da PNAD de 1992 até 2004, ${ }^{14}$ e dos Censos de 1970, 1980, 1991 e 2000. Assim, realizamos os testes de linearidade sem realizar correções nas estimações e comparando ao se incorporar o desenho amostral da PNAD. O mesmo procedimento foi realizado no cálculo das TIRs que envolvem as especificações paramétricas e não paramétricas.

A subpopulação utilizada no teste de linearidade foi: indivíduos, entre 24 e 56 anos, apenas homens brancos, que não frequientam escola, com uma jornada de trabalho superior a 36 horas e inferior a 44 horas, com renda positiva ${ }^{15}$ e abaixo de 100 salários mínimos reais, excluindo os trabalhadores do setor agrícola e público, na produção para o próprio consumo, na construção para o próprio uso e os não remunerados.

A exclusão dos trabalhadores agrícolas e funcionários públicos é devida ao fato que seu regime de salários é diferente do mercado. A remoção dos que freqüentam escola é para efeitos de comparação com o modelo minceriano, que assume que o indivíduo entra no mercado de trabalho um período após o encerramento de sua escolarização. Adicionalmente, notamos da quinta coluna das Tabelas A-1 A-2, no Apêndice, que em torno de $10 \%$ apenas dos trabalhadores estudam, mas esta porcentagem tem se elevado ao longo dos anos. Dentre estes que trabalham e estudam, a maioria é de homens e, dentre os homens, de brancos. Mas estes grupos têm decaído relativamente nos últimos anos.

A restrição da faixa etária pode ser observada da nona a décima-segunda colunas das tabelas. A grande maioria dos trabalhadores tem 24 ou mais anos de idade, e tem se elevado nas últimas duas décadas, em detrimento das outras faixas etárias. Além de ser o maior grupo, esta faixa têm uma renda média em torno de 1000 reais em termos reais, ${ }^{16}$ estando de $100 \%$ a 400\%, aproximadamente, acima da segunda e quarta maiores faixas etárias, respectivamente. Assim, a não inclusão dos grupos menores na realização dos testes e no cálculo das TIRs compreende uma parte relativamente menor dos custos de oportunidade dos rendimentos sacrificados. ${ }^{17}$ Em relação à restrição de 56 anos, nota-se do universo de aposentados que, a grande maioria está acima de 56 anos. A idade média deste grupo está em torno de 63 a 66 anos. No entanto, esta é uma medida que sobreestima a idade real da entrada na aposentadoria, a qual foi considerada devido a falta de uma variável que a mensurasse corretamente.

A restrição da jornada de trabalho para período integral, se deve ao fato que, segundo Freeman (1987), o modelo de investimento em capital humano, proposto por Becker, afirma que um indivíduo deve a cada ano decidir se vai para a escola e investe em educação ou vai para o mercado de trabalho em período integral. Outros estudos importantes, como Murphy e Welch $(1992,1990)$, que se baseiam no modelo minceriano para estimar os perfis de rendimentos dos indivíduos, também restringem a amostra para trabalhadores de tempo integral.

Em relação à exclusão das mulheres, citamos duas razões, a saber: (i) a inserção das mulheres no mercado de trabalho é mais tardia, ocorrendo em média com 14 a 15 anos, enquanto os homens iniciam um ano antes; (ii) Cameron e Heckman (2001),(apud Sachsida et alii (2004)), em um estudo sobre as fontes de disparidade étnica e racial na matrícula escolar, consideram apenas homens pois suas decisões de escolaridade são menos complicadas por considerações de fertilidade.

\subsection{Teste de Linearidade}

No teste de linearidade, foram utilizadas três especificações distintas. De forma geral, estimamos:

$$
\ln Y=\alpha+\beta_{1} x+\beta_{2} x^{2}+\beta_{3} s+\text { especificação } o_{k}+e, k=1,2,3,
$$

\footnotetext{
${ }^{14}$ Excetuando-se os anos de 1994 e 2000, nos quais não foi realizada a pesquisa. Além disso, em 2004, o IBGE incluiu na pesquisa a zona rural da região Norte, antes não incorporada. Então, para efeitos de comparação com os outros anos retiramos a zona rural da região Norte de 2004.

${ }^{15}$ Ao corrigirmos o viés de seleção amostral, incluímos os que não trabalham.

${ }^{16} \mathrm{~A}$ renda neste artigo foi deflacionada pelo INPC a preços de novembro de 2004.

${ }^{17}$ Este ponto é retomado na seção 5.2 que discute as hipóteses assumidas no cálculo das TIRs.
} 
Tabela 1 - Censo 1980

\begin{tabular}{cc}
\hline Faixas horárias & Valor assumido \\
\hline menos $15 \mathrm{hs}$ & 15 \\
de 15 a $29 \mathrm{hs}$ & 22 \\
de 30 a $39 \mathrm{hs}$ & 34.5 \\
de 40 a 48 hs & 44 \\
de 49 hs e mais & 49
\end{tabular}

Tabela 2 - Censo 1970

\begin{tabular}{cc}
\hline Faixas & Valor assumido \\
\hline menos de 15 hs & 15 \\
de 15 a 39 hs & 27 \\
de 40 a 49 hs & 44.5 \\
de 50 hs e mais & 50
\end{tabular}

em que, $Y$ é o salário-hora. ${ }^{18}$

Na especificação 1, utilizamos uma função spline:

$$
\text { especificação }_{1}=\sum_{j=1}^{15} \beta_{j} S_{j},
$$

em que, $S_{j}, j=2, \ldots, 15$, é uma dummy se o agente tem $S \geqslant j$ anos de estudo. Estas dummies captam o retorno educacional, permitindo descontinuidades e mudanças de inclinação após cada ano de estudo completo. Na especificação 2, utilizamos uma função cúbica:

$$
\text { especificação } 2=\beta_{4} S_{4}+\beta_{5} S_{8}+\beta_{6} S_{11}+\beta_{7} S_{15}+\beta_{7} S^{2}+\beta_{8} S^{3},
$$

em que, incluímos também algumas variáveis que captam descontinuidades, ${ }^{19}$ definição similar à 3 . Por fim, estimamos a especificação 3 mais ampla, que permite obter estimativas de cada série cursada. Assim, não utilizamos mais anos de estudo, e sim se o indivíduo obteve a conclusão de determinada série. Optou-se também por esta especificação, visto que alguns agentes obtêm os graus escolares (EF, EM etc) ${ }^{20}$ com menos ou mais anos de estudo que o padrão da maioria. Para isso, substituímos $S$ na equação 3 pela variável $\operatorname{grau} .^{21} \mathrm{E}$ assim a especificação 3 é descrita como:

$$
\begin{array}{r}
\text { especificação } o_{3}=\sum_{j=1}^{4} \beta_{3+j} E F_{j}+\sum_{j=5}^{8} \beta_{3+j} E F_{j}+\sum_{j=1}^{3} \beta_{11+j} E M_{j} \\
+\sum_{j=1}^{4} \beta_{14+j} S U P_{j}+\beta_{19} M D .
\end{array}
$$

As variáveis $E F_{j}, E M_{j}, S U P_{j}$ e $M D$ são dummies se o indivíduo tem o grau $\geq j$ apresentando o mesmo aspecto técnico da especificação $1 .^{22}$

Assim, efetuamos um teste $F$, sobre os coeficientes das especificações descritas afim de testar a hipótese nula favorável ao modelo linear, contra a hipótese alternativa favorável à não-linearidades nos retornos.

É importante ressaltar aqui as diferenças entre a especificação das séries equação 5 e de anos de estudo equação 3 e 4. A variável anos de estudo, na PNAD, é derivada da variável série. Portanto,

\footnotetext{
${ }^{18}$ Mais precisamente: $Y=($ renda do trabalho principal/número de horas trabalhadas $* 4)$. Ressalta-se que para os censos de 1980/1970 as horas de trabalho estavam disponíveis apenas por faixas. Assim os valores assumidos seguem da tabela 1. Com exceção dos limites inferiores e superiores, os valores tomados referem-se a média da faixa horária. Devido à divisão por faixas, a amostra para 1980/1970 incorpora somente os agentes de 40 a 48/49 hs.

${ }^{19}$ A especificação 2 é baseada em Hungerford e Solon (1987), que capta efeitos diplomas nos anos de conclusão referentes aos graus escolares (primário $\left[S_{4}\right]$, ginasial $\left[S_{8}\right]$, secundário $\left[S_{11}\right]$ e terciário $\left[S_{15}\right]$ ).

${ }^{20}$ As seguintes abreviações serão utilizadas daqui em diante em todo artigo. $N E D U C$ : sem instrução, $P R E$ : pré-escola, $E F_{j}$ : j-ésima série do Ensino Fundamental, $E M_{j}$ : j-ésima série do Ensino M édio, $S U P_{j}$ : j-ésima série do Ensino Superior, $M D$ : Mestrado/Doutorado.

${ }^{21}$ Grau recebe os seguintes valores: 0, se nunca estudou, 1 se fez até a pré-escola ou alfabetização, 2 se $1^{a}$ série do EF, 3 se $2^{a}$ série do EF e assim sucessivamente até 17 se cursou o mestrado ou doutorado.

${ }^{22}$ As omissões de dummies relevantes para se evitar dependência linear perfeita na matriz de regressores foram realizadas.
} 
Testando as Hipóteses do Modelo de Mincer para o Brasil

quem cursou até a $4^{a}$ série do EF tem necessariamente 4 anos de estudo, ou seja, esta variável não capta diretamente atrasos ou repetências escolares. No entanto, quem não se instruiu ou quem fez somente pré-escola apresenta o mesmo valor de 0 anos de estudo, logo estes dois grupos não serão diferenciados na especificação de anos de estudo, ao passo que na especificação das séries é possível e serão diferenciados. Ressaltamos que a idade de início dos estudos tomada como referência base é 6 anos. Outro aspecto é que a PNAD tem como limite máximo 15 anos ou mais de estudo. Assim, podem existir diferenças de quem fez curso superior e mestrado/doutorado. Além disso, a especificação da série leva em consideração se o indivíduo concluiu ou não os graus. Em relação ao Censo, temos a mesma estrutura, mas a variável anos de estudo é mais dividida, tendo como maior valor 17 ou mais anos de estudo, com exceção dos anos de 1970 e 1980 que não apresentam esta variável, e portanto estimamos apenas a especificação das séries para estes anos.

\subsubsection{Seleção Amostral}

Na subseção 4.2 foi especificada a amostra a ser utilizada condicionada às variáveis explicativas, ou seja, filtrada por raça, gênero, idade etc. Mas problemas de viés de seleção amostral podem surgir se eu condiciono a amostra na variável dependente, ou seja, se considero na amostra somente indivíduos com salário positivo. O problema de seleção amostral surge pelo fato de não observarmos a oferta de salário-hora dos agentes que não trabalham, ou seja, quando esta oferta salarial for menor que o salário de reserva do indivíduo. Assim, alguns agentes decidem não trabalhar, mas, como já mencionado na subseção 4.1, tomamos como hipótese que a oferta de salário deles é também considerada por aqueles que estão tomando a decisão de quanto devem se educar, pois estes indivíduos "excluídos"da amostra selecionada estão em idade ativa de trabalho. A não incorporação destes agentes viesaria os retornos educacionais.

Para corrigir tal viés, utilizamos o procedimento de estimação de dois estágios de Heckman (1979), no qual estimamos, em uma primeira etapa, um probit utilizando toda a amostra, com uma dummy se o agente está empregado como variável dependente. Esta é a chamada equaç ão de seleção. Assim, obtemos a razão inversa de Mills e estimamos a equação de salários incorporando esta razão. Um teste t sobre o parâmetro desta razão de Mills é um teste válido da hipótese nula de não existência de viés de seleção. ${ }^{23}$

Para a equação de seleção, utilizamos, além das covariáveis da equação de salários, o número de filhos, dummy para casamento, renda não oriunda do trabalho, dummy se o agente pertence a algum sindicato e dummies para os estados de residência. ${ }^{24}$

\subsubsection{Resultados}

No Apêndice seguem as Tabelas A-3 e A-6 dos testes de linearidade para as especificações definidas. Sob todas as especificações estimadas, rejeita-se a hipótese nula de que os coeficientes nos termos não lineares sejam nulos. Além disso, para todas as especificações nota-se que o valor da estatística apresenta uma tendência de crescimento, o que nos leva a concluir que a hipótese de linearidade do modelo de Mincer tem se tornado cada vez mais inadequada, levando a uma má especificação dos modelos que a utilizam. Em relação ao Censo, a estatística $F$ tem se elevado para as duas primeiras especificações, enquanto para a última tem oscilado, mas mostrando-se de forma elevada.

\footnotetext{
${ }^{23}$ Rejeitou-se tal hipótese nula implicando em existência de viés de seleção amostral.

${ }^{24} \mathrm{O}$ número de filhos é computado diretamente somente para as mulheres. Assim, para computarmos esta variável para os homens, identificamos os filhos presentes na família, sendo o pai o chefe ou pessoa de referência. Para a dummy de casamento, procedemos da mesma forma, computando valor 1 para as pessoas que são chefe e cônjuge na família, visto que para a PNAD não existe tal variável. A variável sindicato não foi incluída nas regressões envolvendo o Censo, pois este não a abrange. $\mathrm{E}$ para o Censo de 1970 não foi computada a renda oriunda do não-trabalho, pois somente está disponível a renda da ocupação principal.
} 
Comparando as correções feitas aos modelos, nota-se que a inclusão do plano amostral e a correção do viés de seleção mostral através do heckit reduz a estatística do teste $\mathrm{F}$, mas não a ponto de não se rejeitar a hipótese nula de linearidade da educação.

Portanto, rejeitamos fortemente a hipótese de linearidade para o Brasil, o que por si só já invalidaria a interpretação do coeficiente minceriano ser considerado um retorno educacional.

\subsection{Teste de Paralelismo}

Estimativas iniciais dos rendimentos como função da experiência para diversos níveis de educação serão reportadas. Para se obter tais estimativas, desejamos estimar a seguinte equação:

$$
y=f(x)+u,
$$

tal que $E[u \mid x]=0$ e $E\left[u^{2} \mid x\right]<\infty$, o que implicaria que $E[y \mid x]=f(x)$. Portanto, uma estimativa para $f(x)$ provê um estimador da média de $y$ condicional em $x$. Para estimarmos $f(x)$, temos a abordagem paramétrica (global) que impõe uma forma funcional a $f(x) .^{25}$ Assim, poderíamos impor que $f(x)=$ $a x+b x^{2}+c x^{3}$, ou um polinô mio de ordem maior. A desvantagem deste método é que quanto maior a ordem do polinômio, maior são os problemas inerentes de multicolinearidade, sendo que as estimativas perdem em precisão e parcimônia. Além disso, estas técnicas são sensíveis a outliers, dado o fato de que as estimativas em cada ponto dependem da amostra inteira. Mas um dos maiores problemas referentes a métodos paramétricos é a imposição de uma forma funcional ao modelo a ser estimado, o que pode ocasionar problemas de má especificação. Assim, lançamos mão de uma abordagem local, utilizando o método de regressão linear local não paramétrica. A idéia deste método é minimizar, em uma vizinhança em torno dos pontos de um grid $\left(x_{0}\right)$, a soma dos resíduos quadráticos ponderados pelo formato e largura de uma seqüência de núcleos ( kernels) $\left\{K\left(\frac{x_{i}-x_{0}}{h_{n}}\right)\right\}_{i=1}^{n}$ Härdle (1990). Assim, para uma amostra aleatória $\left\{x_{i}\right\}_{i=1}^{n}$ i.i.d., temos que:

$$
\left(\widehat{m}\left(x_{0}\right), \widehat{b}\left(x_{0}\right)\right)=\arg \min _{m, b} \sum_{i=1}^{n}\left[\left\{y_{i}-m-b\left(x_{i}-x_{0}\right)\right\}^{2} K_{i}\right],
$$

em que, $K_{i}=K\left(\frac{x_{i}-x_{0}}{h_{n}}\right)$ é um núcleo quártico ${ }^{26} \mathrm{e} h_{n}$ é uma janela tal que $h_{n} \stackrel{n \longrightarrow \infty}{\longrightarrow} 0$. Das condições de primeira ordem obtemos:

$$
\begin{gathered}
\widehat{m}\left(x_{0}\right)=\sum_{i=1}^{n} y_{i} W_{i}\left(x_{0}\right), \\
\text { em que, } W_{i}\left(x_{0}\right)=\frac{K_{i}\left[\sum_{i=1}^{n}\left(x_{i}-x_{0}\right)^{2} K_{i}\right]-\left(x_{i}-x_{0}\right) K_{i}\left[\sum_{i=1}^{n}\left(x_{i}-x_{0}\right) K_{i}\right]}{\sum_{i=1}^{n} K_{i}\left[\sum_{i=1}^{n}\left(x_{i}-x_{0}\right)^{2} K_{i}\right]-\left[\sum_{i=1}^{n}\left(x_{i}-x_{0}\right) K_{i}\right]^{2}} .
\end{gathered}
$$

\footnotetext{
${ }^{25}$ Tais métodos seriam, por exemplo, aproximação polinomial global e splines, sendo estes já utilizados nos testes de linearidade. ${ }^{26} \mathrm{O}$ núcleo quártico é definido como:
}

$$
K(t)= \begin{cases}(15 / 16)\left(t^{2}-1\right)^{2} \text { se }|t|<1 \\ 0, & \text { caso contrário }\end{cases}
$$


Assim, $\widehat{m}$ e $\widehat{b}$ são estimadores para $f\left(x_{0}\right)$ e $f^{\prime}\left(x_{0}\right)$ respectivamente. ${ }^{27}$ Assim, a hipótese nula para o teste de que os perfis do log rendimento-experiência são paralelos entre anos de estudos diferentes é:

$$
H_{0}:\left\{\begin{array}{l}
{\left[E\left(y_{i} \mid x_{10}, s=s_{1}\right)-E\left(y_{i} \mid x_{10}, s=s_{2}\right)\right]-\left[E\left(y_{i} \mid x_{20}, s=s_{1}\right)-E\left(y_{i} \mid x_{20}, s=s_{2}\right)\right]=0} \\
{\left[E\left(y_{i} \mid x_{20}, s=s_{1}\right)-E\left(y_{i} \mid x_{20}, s=s_{2}\right)\right]-\left[E\left(y_{i} \mid x_{30}, s=s_{1}\right)-E\left(y_{i} \mid x_{30}, s=s_{2}\right)\right]=0}
\end{array},\right.
$$

em que, $x_{i}$, corresponde a $i$ anos de experiência para $i=10,20,30$. Assim, a idéia do teste é simples: verificar se a diferença da média do salário condicional no nível escolar $s_{2}$ em relação a $s_{1}$ é a mesma em dois níveis distintos de experiência. ${ }^{28,29}$ Segundo Heckman et alii (1998), para testar esta independência de média em $L$ valores diferentes de $x$, seleciona-se os valores de $x_{i}$ separados por pelo menos duas vezes a janela $\left(2 h_{n}\right)$, tal que as estimativas sejam independentes e assim a estatística seja assintóticamente distribuída por $\chi^{2}(L)$. Como utilizamos $h_{n}=5$, por isso selecionou-se valores de $x_{i}$ espaçados de $10 \mathrm{em} 10 .^{30}$ Logo, sendo $\widehat{m}_{x_{i}, s_{l}}$ a estimativa de $E\left(y_{i} \mid x_{i}, s=s_{l}\right)$, a estatística do teste de paralelismo para a hipótese nula definida acima será, segundo Heckman et alii (1998):

$$
\begin{aligned}
& \widehat{\Delta}^{\prime} \widehat{\Phi}^{-1} \widehat{\Delta} \stackrel{d}{\longrightarrow} \chi^{2}(L), L=3, \\
& \widehat{\Delta}=M \cdot\left[\widehat{m}_{x_{10}, s_{2}}, \widehat{m}_{x_{10}, s_{1}}, \widehat{m}_{x_{20}, s_{2}}, \widehat{m}_{x_{20}, s_{1}}, \widehat{m}_{x_{30}, s_{2}}, \widehat{m}_{x_{30}, s_{1}}\right]^{\prime}, M=\left[\begin{array}{cccccc}
1 & -1 & -1 & 1 & 0 & 0 \\
0 & 0 & 1 & -1 & -1 & 1
\end{array}\right] \\
& \text { e } \\
& \begin{array}{r}
\widehat{\Phi}=M \cdot \operatorname{diag}\left(\operatorname{Var}\left(\widehat{m}_{x_{10}, s_{2}}\right), \operatorname{Var}\left(\widehat{m}_{x_{10}, s_{1}}\right), \operatorname{Var}\left(\widehat{m}_{x_{20}, s_{2}}\right), \operatorname{Var}\left(\widehat{m}_{x_{20}, s_{1}}\right),\right. \\
\left.\operatorname{Var}\left(\widehat{m}_{x_{30}, s_{2}}\right), \operatorname{Var}\left(\widehat{m}_{x_{30}, s_{1}}\right)\right) \cdot M^{\prime}
\end{array}
\end{aligned}
$$

Para computar a variância utilizamos o estimador proposto por Heckman et alii (1996b):

$$
\operatorname{Var}\left(\widehat{m}_{x_{i}}, s_{l}\right)=\sum_{i=1}^{n} W_{i}\left(x_{0}, s_{l}\right)^{2} \widehat{\varepsilon}_{i}^{2},
$$

em que, $\widehat{\varepsilon}_{i}$ é o resíduo da regressão.

\subsubsection{Resultados}

Os gráficos dos perfis de renda-experiência foram obtidos através do estimador não paramétrico 6 para diversos níveis educacionais. ${ }^{31}$ Tomando como referência a Figura A-1 do Censo, que apresenta

${ }^{27}$ Intuitivamente estamos utilizando uma aproximação polinomial local, através de uma expansão de Taylor de ordem $p, p=1$, em torno de $x_{0}$. No caso geral teríamos:

$$
\sum_{i=1}^{n}\left[\left\{y_{i}-m-a_{1}\left(x_{i}-x_{0}\right)-a_{2}\left(x_{i}-x_{0}\right)^{2}-\ldots-a_{k}\left(x_{i}-x_{0}\right)^{p}\right\}^{2} K_{i}\right]
$$

em que, $\widehat{a_{2}}$ é um estimador para $\frac{f^{\prime \prime}\left(x_{0}\right)}{2}$. No caso de $p=0, \widehat{m}$ seria o conhecido estimador Nadaraya-Watson.

${ }^{28}$ Além deste teste conjunto, efetuamos também testes separadamente para apenas uma diferença de médias, ou seja, para a hipótese nula:

$$
\left[E\left(y_{i} \mid x_{j}, s=s_{1}\right)-E\left(y_{i} \mid x_{j}, s=s_{2}\right)\right]-\left[E\left(y_{i} \mid x_{l}, s=s_{1}\right)-E\left(y_{i} \mid x_{l}, s=s_{2}\right)\right]=0,
$$

para $l \neq j,(l, j)$ igual a $(10,20)$ e $(20,30)$.

${ }^{29}$ Estes valores para $i(10,20,30)$ são válidos para comparação dos níveis escolares 15 ou mais anos de estudo (acima de SUP), 11 anos (EM3) e 8 anos (EF8). Mas os que envolvem 4 (EF4) e zero (PRE e NEDUC) anos de estudo, a faixa de anos de experiência não engloba 10 anos, logo os valores assumidos são $\{20,30,40\}$.

${ }^{30}$ Realizamos estimativas para janelas variando de 2 a 10 e houve pouca alteração na suavização dos perfis de renda. Assim, escolhemos, através de um critério subjetivo, uma janela intermediária, semelhante a HLT.

${ }^{31}$ Os gráficos apresentados referem-se apenas a alguns anos. Os outros anos podem ser requisitados ao autor. 
medidas relativamente mais estáveis, notamos que os rendimentos tendem a ser uma função mais íngrime e côncava quanto maior o nível educacional. Este ponto está de acordo com a literatura Becker (1975), Willis (1986), Psacharopoulos (1994), em que os indivíduos tendem não apenas a ganhar mais com o maior nível educacional, mas apresentam maiores taxas de crescimento, as quais decaem mais rapidamente ao longo da vida de trabalho, para maiores graus de ensino. Uma investigação inicial através destes gráficos aponta contra o paralelismo, dado que alguns perfis de salário acabam se aproximando. No caso da PNAD (Painéis 2 e 4 ) 32 observamos também uma aproximação para alguns níveis, bem como na Figura A-3, que ocorre até um cruzamento dos perfis, comportamentos semelhantes ao observado por HLT.

Nas Tabelas A-7 e A-10 seguem os testes da estatística 7 para a hipótese conjunta, bem como para apenas dois pares de experiência distintos. Em relação às PNADs, notamos que para a maioria dos anos, nas duas especificações, rejeita-se a hipótese nula conjunta de paralelismo, para algum par de anos de estudo (séries) distintos. É importante destacar, dos resultados da PNAD, a grande variação do diferencial salarial, para um dado nível de experiência, de um ano para outro. Um dos motivos desta variação é a falta de um grande número de observações por célula requeridas pelos métodos de estimação não-paramétricos, ocorrida devido à necessidade de aplicação de filtros na amostra da PNAD. Assim, a média condicional estimada nestes pontos tende a oscilar mais de um ano para outro. Esta oscilação também pode ser notada dos gráficos dos perfis. Assim, realizamos também o teste para o Censo que, dada a nossa restrição amostral, inclui um maior número de observações por célula e, portanto, existe uma menor oscilação das estimativas. Para todas estimativas, com exceção do ginásio em relação ao primário em 1991 e 2000, rejeitamos o paralelismo. Assim, na seção a seguir, computamos as TIRs para se medir o viés destas estimativas em relação ao coeficiente minceriano.

\section{TIR}

Para o cálculo das TIRs, utilizamos:

$$
\sum_{x=0}^{l} \frac{\widehat{Y}(x, s+h)}{(1+r)^{h+x}}-\sum_{x=0}^{l} \frac{\widehat{Y}(x, s)}{(1+r)^{x}}=0,
$$

em que, $\widehat{Y}($.$) são os valores ajustados das regressões paramétricas (spline e expansão de Taylor { }^{33}$ ) e nãoparamétricas. Para a especificação de anos de estudo, $h$ é simplesmente a diferença entre dois níveis educacionais. Ou seja, quando comparamos o valor presente dos rendimentos de quem tem 8 e 4 anos de estudo, este h seria igual a 8-4=4 anos. No entanto, quando utilizamos a especificação das séries, devemos considerar o tempo médio esperado de conclusão de cada série ou grau de ensino completo. Assim, quando comparamos o valor presente dos rendimentos de quem tem o ginásio (EF8) com o primário (EF4), o $h$ seria o tempo médio esperado de conclusão do ginásio subtraído do primário. Mas devido a falta desta variável, utilizamos como proxy a idade média dos que freqüentam o determinado

\footnotetext{
32 Devido à aplicação de filtros à amostra, observou-se para algumas células educação-experiência um número muito reduzido de observações para os graus incompletos, principalmente no fim do ciclo de vida. Este é um problema recorrente destes métodos, observado também nos estudos de Murphy e Welch $(1990,1992)$ e HLT que utilizam o CPS (Current Population Survey) e o Censo americano, respectivamente. Por isso, os gráficos da PNAD apresentam apenas os perfis de salários para os graus completos, que têm um número bem maior de observações por célula.

${ }^{33}$ Ao relaxar a hipótese de paralelismo, estimamos as TIRs através da especificação não paramétrica já discutida e através de uma especificação paramétrica, ou seja, uma expansão de Taylor de ordem 2 tal que:
}

$$
\ln Y=\alpha+\beta_{1} \exp +\beta_{2} \exp ^{2}+\beta_{3} S+\beta_{4} S^{2}+\beta_{5}(S \cdot x) .
$$

Esta estimativa foi realizada a fim de se comparar e verificar a discrepância em relação às estimativas não paramétricas. 
grau escolar. ${ }^{34}$ E adicionamos 0.25 à estimativa do $h$, para minimizar o erro de medida que tende a subestimar a idade média de conclusão do dado nível escolar pois a PNAD e o Censo são realizados em meados de agosto-setembro, ou seja, faltando 1/4 de ano para ser concluído. ${ }^{35}$ A seguir, apresentamos os resultados e depois discutimos outras hipóteses levantadas no cálculo das TIRs.

\subsection{Resultados}

As Tabelas A-11 A-13 apresentam as estimativas das TIRs. As primeiras duas linhas de cada ano (Mincer I e II) referem-se ao coeficiente minceriano ${ }^{36}$ dos seus dois modelos originais. Eles são tomados como pontos de referência, para se medir a magnitude do viés em relação às estimativas das TIRs. Logo, as outras linhas referem-se às estimativas das taxas de desconto, relaxando primeiramente linearidade (função spline) (TIR-Não Linear, terceira linha) e depois paralelismo. Para esta última foram estimados modelos paramétricos (expansão de Taylor) (TIR-Não Paralelo param., quarta linha) e não paramétricos (TIR-Não Paralelo n-param., quinta linha). Estas estimativas estão divididas em três blocos de colunas para a PNAD: as regressões estimadas sem qualquer tipo de correção; incluindo o desenho amostral; e incorporando o desenho amostral $e$ corrigindo o viés de seleção amostral através do heckit. E para o Censo: sem correções e estimando pelo heckit.

Notamos, tanto para os Censos como para as PNADs, que o viés ${ }^{37}$ tende a ser positivo para todos níveis educacionais, especificações e tipos de correções; com exceção de quando se compara os maiores anos de estudo, que apresentam viés negativo, principalmente em 2000 . Um ponto importante a ser destacado é que, este viés negativo para os retornos de maior nível educacional, se torna positivo, quando mudamos o foco para a especificação das séries, para todos os tipos de correções. Esta última especificação tende a medir mais corretamente os retornos de cursos superiores, enquanto a dos anos de estudo pode estar misturando retornos de graduação completo, incompleto e pós-graduação. Por isso, observam-se retornos relativamente mais elevados para o nível escolar mais alto na especificação dos anos de estudo (S15-S11 na PNAD e no Censo). Em termos de magnitude, quando incorporamos apenas o desenho amostral da PNAD, o viés chega a uma diferença de mais de 12 pontos percentuais (p.p.) quando comparamos as TIRs não paramétrica e Mincer II de EF4-PRE para o ano de 2003 (16.42\% $3.98 \%$ ). Quando incorporamos o desenho amostral e corrigimos o problema de seleção amostral (heckit) obtemos vieses que chegam também a mais de 12 p.p. quando comparamos as TIRs não linear e Mincer II de EF4-PRE para o ano de 2003 (15.71\% - 3.53\%). Os vieses para os níveis escolares superiores são menores, mas ainda são significativos, podendo chegar à magnitude de quase 7 p.p., por exemplo, para o ano de 1993 nesta mesma última especificação para SUP-EM3. Para o Censo, os vieses são também elevados, podendo chegar a uma diferença de mais de 14 p.p. quando o retorno minceriano em 2000 passa de $17.29 \%$ para $3.03 \%$ para MD-SUP (TIR não-linear) no modelo usando heckit.

Vale notar que as TIRs não linear (terceira linha) e não paramétrica (última linha) diferem pouco. Por exemplo, quando se incorpora o desenho amostral, este viés chega a no máximo 2.08 p.p. na comparação S4-S0 (9.18\% - 7.11\%) de 2001, e a 1.08 p.p. (7.07\% - 5.98\%) quando se compara EF8EF4 de 2003. Em relação ao Censo, chega a quase 2.4 p.p. de viés comparando os dois maiores níveis escolares (S17+-S15) em 2000 e, para as séries, com exceção de 1970, o viés não chega a 1.5 p.p., em

\footnotetext{
${ }^{34}$ Assim, por exemplo, para o ano de 1992, a idade média de quem cursava EF8 era 16.33 anos e a de quem cursava EF4 era de 11.67. A diferença entre estas médias será de 4.66 , maior do que 4 anos, que seria o tempo de conclusão sem repetência. Isso ocorre porque esta proxy para a especificação das séries considera a repetência dos alunos.

${ }^{35}$ Ressalta-se que o INEP provê uma estimativa do tempo médio de conclusão por série, mas esta estava disponível apenas de 1995 até 2001. Assim, para termos estimativas mais homogêneas para fins comparativos construímos esta medida a partir da idade do indivíduo, a qual diferiu pouco da medida do INEP.

$36 \mathrm{O}$ coeficiente minceriano foi ajustado para o tempo contínuo, como: $e^{\widehat{\beta} s}-1=$ retorno minceriano.

${ }^{37} \mathrm{O}$ viés a ser mencionado nesta subseção é sempre baseado em relação ao modelo de Mincer II, o mais amplamente utilizado na literatura, a não ser que seja mencionado em relação a outra TIR como referência base. Assim, entende-se como viés positivo a diferença entre o retorno minceriano e uma determinada TIR sendo positiva.
} 
termos absolutos. Isso nos leva a crer que, apesar de rejeitarmos o paralelismo, a função spline é uma boa aproximação ao se estimar as TIRs. No entanto, quando se compara a última linha com a quarta linha (TIR não paralela paramétrica), observa-se um viés grande. Assim, ao relaxar paralelismo, deve-se optar por uma abordagem não-paramétrica que não incorra em vieses ocasionados pela má especificação do modelo paramétrico.

Destacamos também duas TIRs para dois níveis escolares que se apresentaram relativamente baixas. A TIR de MD-SUP (Censo) é baixa, o que poderia ir contra o senso comum que cursos de pósgraduação elevam substancialmente os retornos. Mas o que torna estes retornos baixos é o tempo médio de conclusão, variando de 5 até 10 anos. Outra TIR é a que compara Pré-escola com os sem instrução (PRE-NEDUC, PNAD). Ela indica que quem não estudou ou fez apenas a Pré-Escola apresenta um diferencial de renda insignificante ${ }^{38}$. Deve-se ressaltar que esta não deve ser tomada como parâmetro para políticas públicas, dada a vasta evidência que investimentos na Pré-Escola aumentam as habilidades, tempo de permanência dos alunos na escola e reduz sua repetência, e conseqüentemente aumenta a produtividade dos indivíduos no mercado de trabalho Heckman e Carneiro (2003). Barbosa Filho e Pessoa (2008) estimam TIR's para a pré-escola, desenvolvendo uma metodologia interessante, na qual quem estuda na Pré-escola aumenta a sua probabilidade de permanência na escola e aumenta a renda de quem a cursa. Assim, eles obtêm taxas da magnitude de 17\%, a qual se mostrou estável nos últimos 10 anos.

Numa análise horizontal da tabela, podemos inferir os ganhos ao se incorporar o desenho amostral e ao utilizar heckit. Em relação à especificação de anos de estudo, nota-se que, para a TIR não linear, pode-se chegar a um viés negativo de quase -1.68 p.p. (12.58\% - 14.26\% comparando S4-S0 em 1993) e um viés positivo de 1.84 p.p. (13.73\% - 11.9\% para S11-S8 em 1996) ao não se incorporar o desenho amostral. De forma geral, a TIR tende a estar subestimada para níveis escolares menores e sobreestimada para níveis escolares mais elevados. E em relação à correção do viés de seleção amostral, os ganhos de estimar por heckit são para todos os níveis educacionais, chegando a um viés positivo de quase 2.56p.p. (8.78\% - 6.21\%, em 2002) comparando S4-S0 para a PNAD e a quase 14.4 p.p. (26.26\% - 12.82\%, em 2000) para o Censo comparando S17+-S15. Além disso, na maioria dos casos, o viés é positivo, o que implica que os retornos são menores ainda quando corretamente estimados. Assim, é altamente recomendável ao se estimar algum modelo, incluir o desenho amostral da PNAD e corrigir o viés de seleção amostral para a PNAD e Censo.

Assim, esses aspectos apontam para uma direção clara que os retornos mincerianos são viesados, diferindo bastante dos verdadeiros retornos educacionais mensurados pela TIR. Portanto, esse viés tem conseqüências particulares como os retornos estarem sobreestimados e assim não explicarem adequadamente os movimentos de demanda por educação. Logo, para o Brasil, retornos são bem menores quando corretamente mensurados. Isso ocorre devido, principalmente, à especificação das séries que não têm sido considerada na literatura, e como pode ser observado das Tabelas A-11 e A-12, provê retornos bem menores do que a abordagem dos anos de estudo, pois considera o tempo médio esperado de conclusão, ou seja, o termo $h$ é maior para a primeira abordagem do que para a última.

Destacamos ainda que as TIRs da abordagem dos anos de estudo são próximas das obtidas por Barbosa Filho e Pessoa (2008), com exceção do ginasial e do terciário que diferiram em maior magnitude. Além disso, apresentam alguma semelhança com os estudos baseados no modelo de Mincer, como Blom e Verner (2001), pois estes autores obtiveram retornos do primário e ginásio bem menores em relação ao secundário e terciário. Logicamente, são viesados pela evidência apresentada em nosso estudo, sendo que nossos retornos (TIRs) obtidos são maiores para o primário e ginasial e menores para o secundário

\footnotetext{
${ }^{38} \mathrm{Em}$ geral este retorno é bem baixo - podendo até ser negativo - o que era esperado, pois o mercado não tenderá a pagar muito mais para quem só estudou Pré-Escola ou quem nunca estudou. Por parte da decisão dos indivíduos estudarem só até a Pré-Escola uma explicação possível pode ser devido à qualidade dos pais (pois são estes que investem na educação dos filhos quando menores), a qual poderia ter como proxy seu nível educacional (dos pais) que seria baixo para esse grupo. Este é um aspecto interessante que pode servir de pesquisa futura.
} 
e superior. Esta mesma semelhança ocorre com os estudos de Fernandes e Filho (2000), Leal e Werlang (1991) e de Ueda (2002). São também próximos dos obtidos por Sachsida et alii (2004), com exceção do retorno do ginásio. Portanto, de forma geral, os retornos são razoavelmente próximos, com exceção do retorno ginasial que difere entre os estudos. Esta diferença pode ser causada por métodos e amostras distintos entre os artigos.

Dada a imensa gama de retornos estimados, surge a questão: qual é a TIR de cada grau escolar? Em relação às especificações, a das séries é a mais precisa pois incorpora o tempo médio esperado, cuja importância já foi destacada. No entanto, para comparação com outros trabalhos, apresentamos também a especificação dos anos de estudo. Em relação às correções, tomamos como referência os modelos com maiores correções, a saber: (i) não paramétrico e (ii) heckit paramétrico. O primeiro sem problemas de forma funcional e o segundo corrigindo o viés de seleção amostral. Assim, apresentamos dois modelos que realizam correções em dimensões diferentes, e, portanto, a diferença entre eles não é trivial de se medir. ${ }^{39}$ No entanto, ressaltamos que, para ambas as bases notamos que estas estimativas de referência são pouco sensíveis à escolha de modelagem. Portanto, tomamos como referência a TIR não-paramétrica e a TIR paramétrica (Heckit) para uma análise da evolução temporal. Diversos estudos, como já apontado Blom e Verner (2001), indicam uma queda dos retornos mincerianos para o Brasil, com exceção do nível superior, vis a vis um aumento da matrícula de todos os níveis escolares. Da Figura A-5, observamos mais facilmente a evolução temporal. Em relação ao Censo (Gráficos 5.3 e 5.4), os níveis de educação EF4-NEDUC, EM3-EF8 e MD-SUP aumentaram ou mantiveram-se estáveis em 1991 em relação à 1970 e/ou 1980 e decaíram na última década. EF8-EF4 decaiu ao longo das décadas e o SUP-EM3 elevou-se na última década. Em relação à PNAD (Gráficos 5.1 e 5.2), que analisa a evolução recente, notamos para ambas as referências um comportamento próximo do Censo para a última década.

\subsection{Discussão}

Alguns pontos são discutidos em relação às hipóteses e estimativas consideradas no cálculo da TIR. Uma hipótese assumida por Mincer é que os indivíduos primeiramente se educam e depois entram para o mercado de trabalho. Dois pontos são levantados: (i)segundo a Tabela A-1, poucos trabalham enquanto se educam, mas este percentual tem se elevado ao longo do tempo, o que tem aumentado a quantidade de cursos noturnos no país e; (ii) Mincer assume que custos de educação diretos são compensados pelo trabalho durante os estudos, ou que eles são negligenciáveis. Em relação a este último aspecto do custo da educação, Becker destaca que os investimentos em educação são concentrados em idades precoces, pois: (i) com o passar do tempo o indivíduo tem um menor período para retomar o retorno do investimento em capital humano e (ii) o custo de oportunidade vai se elevando com o maior nível de capital humano. Assim, o custo do tempo é uma fonte importante do custo total no cálculo da TIR. Becker assume que na literatura muitas vezes este custo é negligenciado e deve ser tratado do mesmo modo que os custos diretos. Schultz já estendia os custos além das despesas com mensalidades, anuidades e outras, onde os salários sacrificados compõem uma parte significativa. Além disso, Schultz levanta a questão da exclusão dos salários dos estudantes trabalhadores, da qual as estimativas do custo de oportunidade tendem a ser sobreestimadas. Assim, dada também a evidência anterior, de aumento dos estudantes trabalhadores, analisamos uma especificação adicional incluindo os que freqüentam escola a partir das especificações não paramétrica e não linear. Incorporamos também os trabalhadores de tempo parcial (acima de 20 horas de trabalho), pois muitas vezes este grupo para poder estudar, trabalha apenas meio período. No Apêndice, a linha TIR - adicional 1 é comparada com a estimativa não paramétrica,

\footnotetext{
${ }^{39}$ Necessitaríamos de um modelo que corrigisse o problema simultaneamente nas duas dimensões $e$ ainda incorpora-se o desenho amostral da pesquisa. $O$ artigo de Das et alii (2003), como mencionado na nota 5, propõe um heckit não-paramétrico, mas não permite incorporar o desenho amostral. Ou seja, esse é ainda um ponto em aberto na literatura. Desenvolvimentos posteriores nessa linha de pesquisa podem permitir uma análise futura dos ganhos das correções de todos os problemas citados.
} 
incorporando sempre o plano amostral ou peso amostral (Tabela A-14 e A-16), e também partindo da estimativa não-linear com o plano amostral e correção do viés de seleção amostral (Tabela A-15 e A17). Não existe uma grande diferença entre as taxas para todas as especificações. Isso é devido porque o percentual de estudantes trabalhadores apesar de ter se elevado ainda é pequeno.

Uma outra hipótese é que $l^{\prime}(s)=1$, supondo que o tempo de serviço possa não depender dos anos de estudo, podendo variar entre indivíduos com o mesmo nível educacional. Assim, relaxamos também esta hipótese. Vale ressaltar que o tempo de trabalho adotado até aqui é de 32 anos, devido à restrição na faixa etária, ${ }^{40}$ não havendo portanto diferença entre esta hipótese e uma tal que $l^{\prime}(s)=0$. Assim, na linha adicional 2, mantemos a hipótese de que $l^{\prime}(s)=1$, mas com a faixa etária incluindo as pessoas de 10 a 65 anos e com tempo de serviço igual aos primeiros 40 anos; e na linha adicional 3, permitimos que os indivíduos trabalhem até os 65 anos, quando se aposentam $\left(l^{\prime}(s)=0\right) .{ }^{41}$ Notamos uma diferença grande quando incluímos uma faixa etária maior, o que nos mostra que custos sacrificados em idades precoces são significativos; e sua exclusão tende a viesar para baixo os retornos para níveis escolares mais elevados e viesar para cima para as TIRs de S4-S0 e PRE-NEDUC/EF4-PRE para a PNAD. Para o Censo a mesma lógica se aplica. Agora, comparando o adicional 2 com o adicional 3, notamos que as diferenças das estimativas são pequenas. Isso é devido ao fato que os rendimentos no fim do ciclo da vida são mais intensamente descontados, tendo, portanto, pouco impacto no valor presente dos rendimentos e assim pouco impacto na TIR (HLT).

Por fim, incluímos os custos privados diretos (mensalidades) no cálculo da TIR. ${ }^{42}$ Estes custos foram obtidos através da Pesquisa de Orçamentos Familiares (POF) de 1995/1996, ${ }^{43}$ do qual estimamos uma média por nível educacional e ajustamos para uma jornada padrão de 40 horas semanais, para comparação com a renda padronizada pelas horas de trabalho individual. Como os gastos de educação privados estão disponíveis apenas para a POF deste ano, realizamos uma simulação destes gastos para os outros anos para efeitos de comparação. Estimamos a renda total média das famílias que tinham membros na Pré-Escola, depois as que tinham membros no Primário e assim sucessivamente. E calculamos a porcentagem dos gastos com mensalidades em relação à renda média, obtida da POF, e supusemos constante para todos os anos. A partir desta porcentagem estimamos os gastos utilizando a renda média da PNAD da mesma forma. A Tabela A-18 apresenta tais estimativas. Assim, segundo as Tabelas A-14 e A-15, para o ano de 1996, a partir dos gastos originais da POF (linha TIR -adicional 4 (POF)) observamos taxas bem menores, chegando a uma queda de mais 3 p.p. (S15-S11) em relação à especificação 3. Da mesma forma, para os gastos simulados, observamos quedas relativamente grandes para todos anos, principalmente para os maiores níveis educacionais.

Destacamos que as TIRs adicionais 2-4 (Tabelas A-14-A-16) são mais sensíveis entre a modelagem não paramétrica e paramétrica, principalmente em relação ao retorno do ensino ginasial em relação ao ensino primário (EF8-EF4 e S8-S4, PNAD). ${ }^{44}$

\footnotetext{
$\overline{{ }^{40} \text { Ou seja, como } x=i-s-6 \text {, então } \Delta^{\bar{s}}} x=56-24=32$ anos, para um nível $\bar{s}$ de educação fixado. Como consideramos a idade mínima como 24 anos, logo, para esta idade já existem pessoas formadas com o maior nível educacional.

${ }^{41}$ Ressaltamos que as TIRs adicionais 2 e 3 inclui a modificação da TIR adicional 1, e a TIR adicional 4, que será apresentada a seguir, inclui as modificações da TIR adicional 3. Ou seja, estamos relaxando estas hipóteses gradualmente e sucessivamente. A nota da tabela A-14 também reforça este ponto.

42 Mais precisamente, estimamos a TIR através de:
}

$$
\sum_{i=0}^{l} \frac{\widehat{Y}(i, s+h)}{(1+r)^{h+i}}-\sum_{i=0}^{l} \frac{\widehat{Y}(i, s)}{(1+r)^{i}}-\sum_{i=0}^{h} \frac{c}{(1+r)^{i}}=0,
$$

onde, $c$ são os custos médios diretos com mensalidade.

${ }^{43}$ Vale ressaltar que o INEP provê através de sua página na internet dados de apenas gastos públicos com educação. Estes gastos podem ser incluídos na análise das TIRs, em um contexto mais macroeconômico, o qual compara o investimento em educação com outros investimentos, como em capital, como já feito por Langoni (1974).

${ }^{44}$ Este retorno ginasial diverge entre diversos estudos, como mencionado em seção anterior. Tomando como referência as TIRs 
Testando as Hipóteses do Modelo de Mincer para o Brasil

Analisando ao longo dos anos do Censo, notamos, do Gráfico 6.4 na Figura A-6, uma tendência de queda de todos níveis na última década e um aumento da graduação e pós-graduação frente ao grau imediatamente anterior na última década. Estimando por heckit (Gráfico 6.3), notamos uma pequena diferença, em relação aos graus EF4-NEDUC que subiu e MD-SUP que caiu na última década. Em relação à PNAD, notamos que a TIR não-linear (Gráfico 6.1) apresenta comportamento semelhante em relação à seção anterior. A TIR não paramétrica (Gráfico 6.2) apresenta também o mesmo comportamento, com exceção do EF8-EF4 que apresentou uma queda até 1999 e um aumento a partir daí, e o nível superior que apresentou uma certa estabilidade nesta década.

\section{CONCLUSÃO}

Desde a publicação do trabalho seminal de Mincer, em 1958, e posteriormente uma versão estendida, em 1974, vários artigos empíricos têm-se utilizado da regressão minceriana a fim de se estimar a "taxa de retorno"para educação. No entanto, algumas das hipóteses por de trás do modelo original, para que o coeficiente de anos de estudo seja entendido como uma taxa de retorno, são rejeitadas neste artigo (linearidade e paralelismo). Assim, para o Brasil, corroboramos a evidência de estudos internacionais para os EUA. Assim, relaxamos diversas destas hipóteses a fim de se medir o viés originado da má estimação da taxa de retorno. Notamos que o viés tende a ser positivo para todos os níveis educacionais. Assim, as TIRs tendem a ser menores quando as hipóteses são relaxadas, dentre as quais, linearidade, paralelismo e a inclusão dos custos privados tendem a gerar um maior impacto na estimação das TIRs. Uma outra alteração significativa nas TIRs foi a ampliação da faixa etária, passando de 24-56 anos para 10-65 anos. Isso mostra que os custos sacrificados em idades precoces são significativos. Em relação às especificações de anos de estudo e séries, a última acrescenta um aspecto adicional importante na estimação das TIRs em relação à primeira: os agentes considerarem o tempo médio de conclusão das séries. Isto acarreta em uma redução significativa nas TIRs, principalmente para os níveis escolares maiores.

A incorporação do desenho amostral da PNAD é um ganho adicional na literatura empírica para o Brasil, a qual não tem sido considerada na estimação de diversos modelos econômicos. Esta correção apenas corroborou os testes feitos, mas influiu consideravelmente na mensuração correta dos retornos. A correção para o viés de seleção amostral também pode ser considerado um ganho adicional, visto que mesmo estudos recentes, como HLT, não estimaram por heckit, o que altera também a magnitude das TIRs.

Por fim, a maioria das TIRs estimadas tendem a corroborar a evidência da literatura que os retornos educacionais estão decaindo nos últimos anos, com exceção do nível superior que aponta para um crescimento nesta última década, mas em magnitude menor dos obtidos em diversos estudos recentes. Esta estimação correta das taxas de retorno possibilita para pesquisa futura uma análise detalhada das razões do aumento da TIR para o ensino superior, dada a evidência de aumento substancial das taxas de matrícula na última década. E é um indicador chave para direcionar as políticas públicas de diversos governos e órgãos e na avaliação de programas sociais.

\section{BIBLIOGRAFIA}

Barbosa Filho, F. H. \& Pessoa, S. (2008). Retornos da educação no Brasil. Pesquisa e Planejamento Econômico, 38(1):97-125.

Becker, G. S. (1975). Human Capital: A Theoretical and Empirical Analysis, with Special Reference to Education. New York: Columbia Uinversity Press, 2 edition.

adicionais 2-4 notamos que este retorno é bem maior para o não-paramétrico em relação ao não-linear. 
Belman, D. \& Heywood, J. S. (1991). Sheepskin effects in the returns to education: An examination on women and minorities. The Review of Economics and Statistics, 73(4):720-24. available at http://ideas.repec.org/a/tpr/restat/v73y1991i4p720-24.html.

Binelli, C., C. M. \& Filho, N. M. (2006). Education and wages in Brazil. Apresentado no XXVIII Encontro Brasileiro de Econometria.

Blom, A., L. H.-N. \& Verner, D. (2001). Education, earnings, and inequality in Brazil, 1982-98. Peabody Journal of Education, 76(3/4):180-221.

Cameron, S. V. \& Heckman, J. J. (2001). The dynamics of educational attainment for black, hispanic, and white males. Journal of Political Economy, 109(3):455-499. available at http://ideas . repec.org/a/ucp/jpolec/v109y2001i3p455-499.html.

Card, D. (1999). The causal effect of education on earnings. In Ashenfelter, O. \& Card, D., editors, Handbook of Labor Economics, volume 3A, pages 1801-1863. Amsterdam: Elsevier.

Card, D. (2001). Estimating the return to schooling: Progress on some persistent econometric problems. Econometrica, 69(5):1127-60. available at http://ideas.repec.org/a/ecm/emetrp/ v69y2001i5p1127-60.html.

Chromy, J. R. \& Abeyasekara, S. (2005). Statistical analysis of survey data. In of Economic, D. \& of United Nations, S. A., editors, Household Sample Surveys in Developing and Transition Countries, chapter 19, pages 389-417. New York: United Nations.

Das, M., Newey, W. K., \& Vella, F. (2003). Nonparametric estimation of sample selection models. Review of Economic Studies, 70(1):33-58. available at http://ideas.repec.org/a/bla/ restud/v70y2003ilp33-58.html.

de Deus Vieira Silva, N. \& Kassouf, A. L. (2000). Mercados de trabalho formal e informal: uma análise da discriminaçãoo e da segmentação. Nova Economia, 10(1):41-77. available at http: //ideas.repec.org/a/nov/artigo/v10y2000ilp41-77.html.

Fernandes, R. \& Filho, N. A. M. (2000). A evolução da desigualdade no Brasil metropolitano entre 1983 e 1997. Pesquisa e Planejamento Econômico, 30(4):549-569.

Freeman, R. B. (1987). Demand for education. In Ashenfelter, O. \& Layard, R., editors, Handbook of Labor Economics, volume 1 of Handbook of Labor Economics, chapter 6, pages 357-386. Elsevier.

Härdle, W. (1990). Applied nonparametric regression. Cambridge University Press.

Heckman, J., Ichimura, H., Smith, J., \& Todd, P. (1998). Characterizing selection bias using experimental data. Econometrica, 66(5):1017-1098. available at http://ideas.repec.org/a/ ecm/emetrp/v66y1998i5p1017-1098.html.

Heckman, J., Layne-Farrar, A., \& Todd, P. (1996a). Human capital pricing equations with an application to estimating the effect of schooling quality on earnings. The Review of Economics and Statistics, 78(4):562-610. available at http://ideas.repec.org/a/tpr/restat/ v78y1996i4p562-610.html.

Heckman, J. J. (1979). Sample selection bias as a specification error. Econometrica, 47(1):153-61. available at http://ideas.repec.org/a/ecm/emetrp/v47y1979i1p153-61.html.

Heckman, J. J. (2005). Education policy. Apresentado no Econometric Society $9^{t h}$ World Congress, IFS Lecture. 
Heckman, J. J. \& Carneiro, P. (2003). Human capital policy. Discussion Paper 821, IZA.

Heckman, J. J., Ichimura, H., Smith, J., \& Todd, P. (1996b). Making the asymptotic theory of semiparametric estimation empirically relevant. Technical report, University of Chicago.

Heckman, J. J., Lochner, L. J., \& Todd, P. E. (2006). Earnings functions, rates of return and treatment effects: The mincer equation and beyond. In Handbook of the Economics of Education, volume 1, chapter 7, pages 307-458. Hanushek, E. and F. Welch.

Hungerford, T. \& Solon, G. (1987). Sheepskin effects in the returns to education. Review of Economics and Statistics, 69(1):175-177.

IBGE (2004). Pesquisa nacional por amostra e domicílios (2004) - notas metodológicas.

Jaeger, D. A. \& Page, M. E. (1996). Degrees matter: New evidence on sheepskin effects in the returns to education. Review of Economics and Statistics, 78(4):733-740.

Langoni, C. G. (1974). As Causas do Crescimento Econômico do Brasil. Apec Editora S.A.

Leal, C. I. S. \& Werlang, S. R. C. (1991). Retornos em educação no Brasil: 1976/89. Pesquisa e Planejamento Econômico, 21(3):559-574.

Loureiro, P. R. A. \& Carneiro, F. G. (2001). Discriminação no mercado de trabalho: Uma análise dos setores rural e urbano no Brasil. Economia Aplicada, 5(3):519-545.

Lumley, T. (2004). Analysis of complex survey samples. Journal of Statistical Software, 9(8):1-19. available at http://ideas.repec.org/a/jss/jstsof/09i08.html.

Mincer, J. (1958). Investment in human capital and personal income distribution. Journal of Political Economy, 66:281. available at http://ideas.repec.org/a/ucp/jpolec/ v66y1958p281.html.

Mincer, J. (1974). Schooling, Experience, and Earnings. New York:Columbia University Press.

Murphy, K. M. \& Welch, F. (1990). Empirical age-earnings profiles. Journal of Labor Economics, 8(2):202-29. available at http://ideas.repec.org/a/ucp/jlabec/ v8y1990i2p202-29.html.

Murphy, K. M. \& Welch, F. (1992). The structure of wages. Quarterly Journal of Economics, 107(1):285-326.

Park, J. H. (1994). Returns to schooling: A peculiar deviation from linearity. Technical Report 714, Princeton University, Department of Economics, Industrial Relations Section. Returnstoschooling: apeculiardeviationfromlinearity.

Pessoa, D. G. C. \& Silva, P. L. N. (1998). Análise de dados amostrais. $13^{\circ}$ Simpósio Nacional de Probabilidade e Estatística.

Psacharopoulos, G. (1985). Returns to education: a further international update and implications. Journal of Human Resources, 20:583-604.

Psacharopoulos, G. (1994). Returns to investment in education: A global update. World Development, 22(9):1325-1343. available at http://ideas.repec.org/a/eee/wdevel/ v22y1994i9p1325-1343.html. 
Psacharopoulos, G. \& Patrinos, H. A. (2004). Returns to investment in education: a further update. Education Economics, 12(2):111-134. available at http: / / ideas.repec.org/a/taf / edecon/v12y2004i2p111-134.html.

Resende, M. \& Wyllie, R. (2006). Retornos para educação no Brasil: Evidências empíricas adicionais. Economia Aplicada, 10(3):349-365.

Sachsida, A., Loureiro, P. R. A., \& de Mendonça, M. J. C. (2004). Um estudo sobre retorno em escolaridade no Brasil. Revista Brasileira de Economia, 58(2). available at http://ideas. repec.org/a/fgv/epgrbe/4993.html.

Schultz, T. W. (1963). The Economic Value of Education. New York:Columbia University Press.

Silva, P. L. N., Pessoa, D. G. C., \& Lila, M. F. (2002). Análise estatística de dados da pnad: incorporando a estrutura do plano amostral. Ciência \& Saúde Coletiva, 7(4):659-670.

Soares, R. R. \& Gonzaga, G. (1999). Determinação de salários no Brasil: Dualidade ou não-linearidade no retorno à educação? Revista de Econometria, 19(2):367-404.

Ueda, E. M. e. R. H. (2002). Estimando o retorno da educação no Brasil. Economia Aplicada, 6(2):209238.

Willis, R. J. (1986). Wage determinants: A survey and reinterpretation of human capital earnings functions. In Ashenfelter, O. \& Layard, R., editors, Handbook of Labor Economics, volume 1, chapter 10. Amsterdam: Elsevier.

Yansaneh, I. S. (2005). Overview of sample design issues for household surveys in developing and transition countries. In of Economic, D. \& of United Nations, S. A., editors, Household Sample Surveys in Developing and Transition Countries, chapter 2. New York: United Nations.

\section{A. LISTA DE FIGURAS E TABELAS}



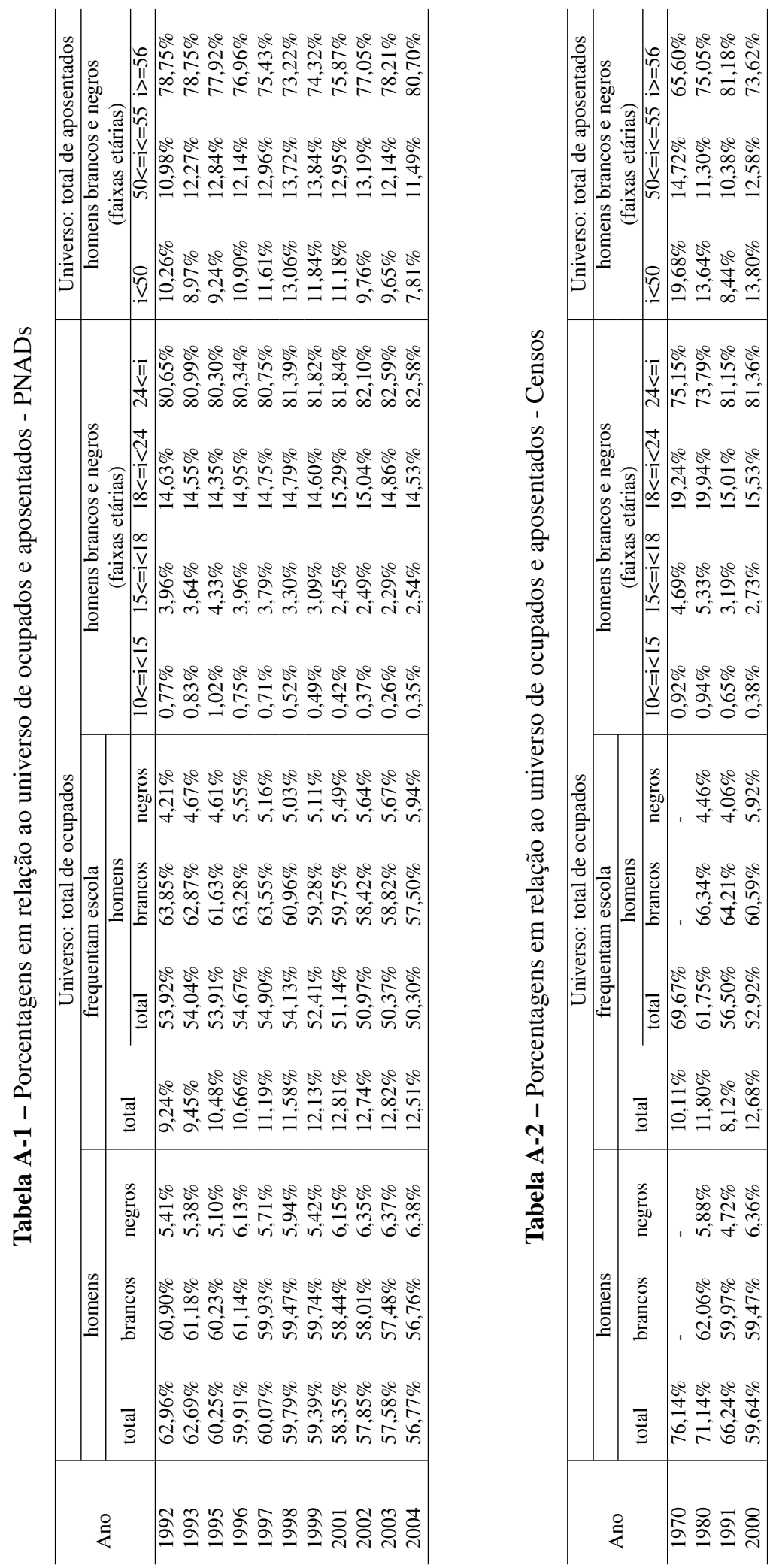
Tabela A-3 - Testes de linearidade da especificação 1 - PNAD

\begin{tabular}{lcccccccccccc}
\hline Correções & Ano & 1992 & 1993 & 1995 & 1996 & 1997 & 1998 & 1999 & 2001 & 2002 & 2003 & 2004 \\
\hline \multirow{2}{*}{ Sem correções } & $\mathrm{N}^{\circ}$ Obs. & 8826 & 8824 & 9587 & 8957 & 9345 & 9064 & 9381 & 9833 & 9982 & 9870 & 10522 \\
& teste F & 11,85 & 15,85 & 22,89 & 15,64 & 18,34 & 23,75 & 24,15 & 34,45 & 46,31 & 39,4 & 49,2 \\
& Prob>F & 0 & 0 & 0 & 0 & 0 & 0 & 0 & 0 & 0 & 0 & 0 \\
\hline \multirow{2}{*}{ Plano } & $\mathrm{N}^{\circ}$ Obs. & 8826 & 8811 & 9567 & 8942 & 9325 & 9044 & 9361 & 9833 & 9958 & 9814 & 10462 \\
Amostral & teste F & 8,11 & 11,3 & 17,23 & 9,47 & 12,54 & 16,79 & 15,04 & 25,59 & 32,19 & 30,4 & 31,2 \\
& Prob>F & 0 & 0 & 0 & 0 & 0 & 0 & 0 & 0 & 0 & 0 & 0 \\
\hline Plano & $\mathrm{N}^{\circ}$ Obs. & 11711 & 11700 & 12636 & 12365 & 2932 & 12973 & 13234 & 13826 & 13980 & 13940 & 14340 \\
Amostral \& & teste F & 7,76 & 11,03 & 18,6 & 9,49 & 13,09 & 16,82 & 14,33 & 26,22 & 32,02 & 30,53 & 30,89 \\
Heckit & Prob>F & 0 & 0 & 0 & 0 & 0 & 0 & 0 & 0 & 0 & 0 & 0 \\
\hline
\end{tabular}

Tabela A-4 - Testes de linearidade da especificação 2 - PNAD

\begin{tabular}{lcccccccccccc}
\hline Correções & Ano & 1992 & 1993 & 1995 & 1996 & 1997 & 1998 & 1999 & 2001 & 2002 & 2003 & 2004 \\
\hline \multirow{5}{*}{ Sem correções } & $\mathrm{N}^{\circ}$ Obs. & 8826 & 8824 & 9587 & 8957 & 9345 & 9064 & 9381 & 9833 & 9982 & 9870 & 10522 \\
& teste F & 24,75 & 32,72 & 51,02 & 33,73 & 40,1 & 52,61 & 51,79 & 75,96 & 104,32 & 90,67 & 111,42 \\
& Prob>F & 0 & 0 & 0 & 0 & 0 & 0 & 0 & 0 & 0 & 0 & 0 \\
\hline \multirow{2}{*}{ Plano } & $\mathrm{N}^{\circ}$ Obs. & 8826 & 8811 & 9567 & 8942 & 9325 & 9044 & 9361 & 9833 & 9958 & 9814 & 10462 \\
Amostral & teste F & 15,76 & 21,3 & 37,09 & 18,44 & 26,35 & 36,64 & 30,38 & 55,71 & 71,35 & 67,36 & 70,2 \\
& Prob>F & 0 & 0 & 0 & 0 & 0 & 0 & 0 & 0 & 0 & 0 & 0 \\
\hline Plano & $\mathrm{N}^{\circ}$ Obs. & 11711 & 11700 & 12636 & 12365 & 12932 & 12973 & 13234 & 13826 & 13980 & 13940 & 14340 \\
Amostral \& & teste F & 3,22 & 6,72 & 10,15 & 6,66 & 11,17 & 7,77 & 6,86 & 16,38 & 16,58 & 16,96 & 14,74 \\
Heckit & Prob>F & 0,01 & 0 & 0 & 0 & 0 & 0 & 0 & 0 & 0 & 0 & 0 \\
\hline
\end{tabular}

Tabela A-5 - Testes de linearidade da especificação 3 - PNAD

\begin{tabular}{lcccccccccccc}
\hline Correções & Ano & 1992 & 1993 & 1995 & 1996 & 1997 & 1998 & 1999 & 2001 & 2002 & 2003 & 2004 \\
\hline \multirow{8}{*}{ Sem correçõoes } & $\mathrm{N}^{0}$ Obs. & 8826 & 8823 & 9587 & 8956 & 9345 & 9064 & 9381 & 9833 & 9981 & 9870 & 10522 \\
& teste F & 10,25 & 14,31 & 22,31 & 14,83 & 17,57 & 20,88 & 23,44 & 32,92 & 43,57 & 36,25 & 46,35 \\
& Prob>F & 0 & 0 & 0 & 0 & 0 & 0 & 0 & 0 & 0 & 0 & 0 \\
\hline Plano & $\mathrm{N}^{0}$ Obs. & 8789 & 8778 & 9537 & 8912 & 9298 & 9021 & 9337 & 9808 & 9934 & 9793 & 10423 \\
Amostral & teste F & 6,59 & 9,39 & 16,04 & 8,49 & 12,36 & 14,61 & 15,55 & 25,91 & 31,77 & 27,34 & 27,82 \\
& Prob>F & 0 & 0 & 0 & 0 & 0 & 0 & 0 & 0 & 0 & 0 & 0 \\
\hline Plano & $\mathbf{N}^{\circ}$ Obs. & 11652 & 11650 & 12578 & 12317 & 12888 & 12933 & 13189 & 13767 & 13938 & 13896 & 14270 \\
Amostral \& & teste F & 6,02 & 8,59 & 17,03 & 8,55 & 12,9 & 14,72 & 14,78 & 25,88 & 30,91 & 27,38 & 27,38 \\
Heckit & Prob>F & 0 & 0 & 0 & 0 & 0 & 0 & 0 & 0 & 0 & 0 & 0 \\
\hline
\end{tabular}

Tabela A-6 - Testes de linearidade das especificações 1 - 3 - Censo

\begin{tabular}{cccccccccc} 
& & \multicolumn{2}{c}{ Especificação 1 } & \multicolumn{2}{c}{ Especificação 2 } & \multicolumn{3}{c}{ Especificação 3 } \\
\hline Correções & Ano & 1991 & 2000 & 1991 & 2000 & 1970 & 1980 & 1991 & 2000 \\
\hline \multirow{3}{*}{ Sem correções } & $\mathrm{N}^{0}$ Obs. & 514457 & 486437 & 514457 & 486437 & 1010984 & 965773 & 514457 & 486437 \\
& teste F & 346,6 & 803,9 & 845,67 & 1955,98 & 586,76 & 762,71 & 414,73 & 212,66 \\
& Prob>F & 0 & 0 & 0 & 0 & 0 & 0 & 0 & 0 \\
\hline \multirow{3}{*}{ Heckit } & $\mathrm{N}^{\circ}$ Obs. & 515213 & 793276 & 515213 & 793276 & 1244886 & 1158103 & 515213 & 793276 \\
& teste F & 343,75 & 685,13 & 742,15 & 1132,51 & 704,66 & 531,98 & 367,13 & 832,89 \\
& Prob>F & 0 & 0 & 0 & 0 & 0 & 0 & 0 & 0 \\
\hline
\end{tabular}


Testando as Hipóteses do Modelo de Mincer para o Brasil

Tabela A-7 - Diferença da média condicional dos rendimentos em log entre dois grupos de anos de estudo por nível de experiência e P-Valor do teste de paralelismo para três hipóteses nulas - PNADs

\begin{tabular}{|c|c|c|c|c|c|c|c|c|c|c|c|}
\hline \multicolumn{12}{|c|}{ Entre $15+$ e 11 anos de estudo (Homens Brancos) } \\
\hline Experiência & 1992 & 1993 & 1995 & 1996 & 1997 & 1998 & 1999 & 2001 & 2002 & 2003 & 2004 \\
\hline 10 & 0,95 & 0,93 & 1,04 & 0,94 & 0,96 & 1,02 & 0,99 & 1,18 & 1,11 & 1,04 & 1,02 \\
\hline 20 & 0,73 & 0,97 & 0,97 & 0,82 & 0,77 & 0,92 & 0,84 & 0,96 & 1,01 & 1,03 & 1,02 \\
\hline 30 & 0,79 & 0,79 & 0,82 & 0,86 & 0,74 & 0,94 & 0,88 & 0,82 & 1,00 & 0,88 & 0,93 \\
\hline \multicolumn{12}{|l|}{$P$-Valor } \\
\hline & 001 & 0,7628 & 0,6419 & 0,0633 & 0,0025 & 0,1205 & 0,03 & 00 & 20 & 0,91 & 0,99 \\
\hline “30- & 8128 & 0,0913 & 0,4330 & 0,9197 & 0,9599 & 0,9819 & 0,88 & 0,1 & 0,98 & $0,8 \varepsilon$ & 0,37 \\
\hline Con & 0,0004 & 0,1880 & 0,1786 & 0,1296 & 0,0009 & 0,2321 & 0,0356 & 0,00 & 0,3340 & 0,96 & 0,46 \\
\hline \multicolumn{12}{|c|}{ Entre 11 e 8 anos de estudo (Homens Brancos) } \\
\hline $\operatorname{Exp}$ & 1992 & 1993 & 1995 & 1996 & 1997 & 1998 & 1999 & 2001 & 2002 & 2003 & 2004 \\
\hline 10 & 0,35 & 0,47 & 0,39 & 0,46 & 0,45 & 0,34 & 0,35 & 0,33 & 0,36 & 0,38 & 0,19 \\
\hline 20 & 0,51 & 0,39 & 0,49 & 0,62 & 0,63 & 0,46 & 0,43 & 0,40 & 0,42 & 0,44 & 0,42 \\
\hline 30 & 0,23 & 0,42 & 0,53 & 0,32 & 0,50 & 0,50 & 0,43 & 0,58 & 0,55 & 0,52 & 0,48 \\
\hline
\end{tabular}

P-Valor

$\begin{array}{llllllllllllllll}\text { "20-10"” } & 0,0463 & 0,8169 & 0,4540 & 0,0202 & 0,0004 & 0,1709 & 0,4896 & 0,1068 & 0,4983 & 0,1578 & 0,0002\end{array}$ $\begin{array}{llllllllllllllllll}\text { “30-20" } \quad 0,0252 & 0,9673 & 0,8753 & 0,0022 & 0,5134 & 0,7652 & 1,0000 & 0,0132 & 0,1162 & 0,4148 & 0,6782\end{array}$ $\begin{array}{llllllllllllllllll}\text { Conjunta }^{* * *} & 0,0364 & 0,9372 & 0,3680 & 0,0028 & 0,0014 & 0,1571 & 0,6320 & 0,0007 & 0,0780 & 0,0278 & 0,0000\end{array}$

\begin{tabular}{llllllllllll}
\hline \multicolumn{10}{c}{ Entre 8 e 4 anos de estudo (Homens Brancos) } \\
\hline Experiência & 1992 & 1993 & 1995 & 1996 & 1997 & 1998 & 1999 & 2001 & 2002 & 2003 & 2004 \\
20 & 0,46 & 0,58 & 0,45 & 0,30 & 0,37 & 0,43 & 0,51 & 0,48 & 0,38 & 0,51 & 0,39 \\
30 & 0,52 & 0,34 & 0,34 & 0,46 & 0,43 & 0,34 & 0,38 & 0,37 & 0,40 & 0,34 & 0,34 \\
40 & 0,46 & 0,64 & 0,47 & 0,42 & 0,77 & 0,15 & 0,27 & 0,35 & 0,45 & 0,19 & 0,33
\end{tabular}

P-Valor

$\begin{array}{llllllllllll}\text { "30-20"" } & 0,8150 & 0,0447 & 0,0527 & 0,1520 & 0,7883 & 0,4326 & 0,1372 & 0,3212 & 0,9000 & 0,0000 & 0,6956\end{array}$ $\begin{array}{lllllllllllllllll}\text { “40-30"** } \quad 0,8710 & 0,1859 & 0,6076 & 0,9215 & 0,0201 & 0,1068 & 0,7454 & 0,9934 & 0,9019 & 0,0933 & 0,9977\end{array}$ $\begin{array}{llllllllllll}\text { Conjunta }^{* * * *} & 0,9269 & 0,0665 & 0,1053 & 0,1998 & 0,0023 & 0,0160 & 0,1675 & 0,4612 & 0,8917 & 0,0000 & 0,7838\end{array}$

\begin{tabular}{lllllllllllll}
\hline \multicolumn{10}{c}{ Entre 4 e 0 anos de estudo (Homens Brancos) } \\
\hline Experiência & 1992 & 1993 & 1995 & 1996 & 1997 & 1998 & 1999 & 2001 & 2002 & 2003 & 2004 \\
20 & 0,49 & 0,64 & 0,62 & 0,45 & 0,37 & 0,54 & 0,57 & 0,28 & 0,30 & 0,16 & 0,40 \\
30 & 0,74 & 0,69 & 0,47 & 0,59 & 0,62 & 0,55 & 0,46 & 0,37 & 0,30 & 0,35 & 0,34 \\
40 & 0,66 & 0,64 & 0,52 & 0,63 & 0,47 & 0,60 & 0,51 & 0,53 & 0,43 & 0,53 & 0,40
\end{tabular}

P-Valor

$\begin{array}{llllllllllllll}\text { “30-20"” } & 0,1204 & 0,9092 & 0,5271 & 0,4894 & 0,0039 & 0,9994 & 0,5256 & 0,4868 & 0,9999 & 0,2678 & 0,9128\end{array}$

$\begin{array}{llllllllllllllllll}\text { “40-30"** } \quad 0,8663 & 0,8883 & 0,9408 & 0,9410 & 0,2612 & 0,9037 & 0,9071 & 0,3189 & 0,6212 & 0,4227 & 0,8821\end{array}$

$\begin{array}{lllllllllllllll}\text { Conjunta }^{* * *} & 0,1009 & 0,9596 & 0,6700 & 0,5551 & 0,0091 & 0,9341 & 0,7169 & 0,1154 & 0,7568 & 0,0023 & 0,9627\end{array}$

\footnotetext{
${ }^{*} H_{0}:\left(m\left(x_{20}, s_{15}\right)-m\left(x_{20}, s_{12}\right)\right)-\left(m\left(x_{10}, s_{15}\right)-m\left(x_{10}, s_{12}\right)\right)=0$

${ }^{* *} H_{0}:\left(m\left(x_{30}, s_{15}\right)-m\left(x_{30}, s_{12}\right)\right)-\left(m\left(x_{20}, s_{15}\right)-m\left(x_{20}, s_{12}\right)\right)=0$

${ }^{* * *} H_{0}:\left(m\left(x_{20}, s_{15}\right)-m\left(x_{20}, s_{12}\right)\right)-\left(m\left(x_{10}, s_{15}\right)-m\left(x_{10}, s_{12}\right)\right)=$

$\left(m\left(x_{30}, s_{15}\right)-m\left(x_{30}, s_{12}\right)\right)-\left(m\left(x_{20}, s_{15}\right)-m\left(x_{20}, s_{12}\right)\right)=0$

Estas hipóteses são exemplificadas para o primeiro painel da tabela acima. As mesmas se aplicam para os outros painéis, alterando-se os valores de x e s. As áreas sombreadas referem-se aos p-valores da hipótese conjunta maiores do que 0.05. Esta nota vale também para as Tabelas A-8-A-10.
} 
Tabela A-8 - Diferença da média condicional dos rendimentos em log entre dois grupos de anos de estudo por nível de experiência e P-Valor do teste de paralelismo para três hipóteses nulas - Censo

\begin{tabular}{rcccccccc}
\hline & $15+\mathrm{e} 11$ anos & \multicolumn{2}{c}{$11 \mathrm{e} 8$ anos } & \multicolumn{2}{c}{8 e 4 anos } & \multicolumn{2}{c}{4 e 0 anos } \\
\hline experiência & 1991 & 2000 & 1991 & 2000 & 1991 & 2000 & 1991 & 2000 \\
10 & 0,92 & 1,07 & 0,43 & 0,39 & 0,45 & 0,42 & 0,51 & 0,45 \\
20 & 0,81 & 0,98 & 0,51 & 0,48 & 0,45 & 0,45 & 0,62 & 0,52 \\
30 & 0,65 & 0,88 & 0,50 & 0,51 & 0,43 & 0,43 & 0,63 & 0,58 \\
$P$-Valor & & & & & & & & \\
"20-10"* & 0,0000 & 0,0000 & 0,0000 & 0,0000 & 0,8269 & 0,0206 & 0,0000 & 0,0000 \\
"30-20"** & 0,0000 & 0,0000 & 0,6671 & 0,0126 & 0,3451 & 0,2475 & 0,5734 & 0,0034 \\
Conjunta*** & 0,0000 & 0,0000 & 0,0000 & 0,0000 & 0,4328 & 0,0633 & 0,0000 & 0,0000 \\
\hline
\end{tabular}


Tabela A-9 - Diferença da média condicional dos rendimentos em log entre dois grupos de anos de estudo por nível de experiência e P-Valor do teste de paralelismo para três hipóteses nulas - PNAD

\begin{tabular}{|c|c|c|c|c|c|c|c|c|c|c|c|}
\hline \multicolumn{12}{|c|}{ Diferença da média condicional dos rendimentos em log entre SUP4+ e EM3 (Homens Brancos) } \\
\hline experiência & 1992 & 1993 & 1995 & 1996 & 1997 & 1998 & 1999 & 2001 & 2002 & 2003 & 2004 \\
\hline 10 & 0,72 & 0,71 & 0,52 & 0,47 & 0,52 & 0,58 & 0,66 & 0,80 & 0,84 & 0,92 & 0,95 \\
\hline 20 & 0,65 & 0,72 & 0,49 & 0,47 & 43 & 0,59 & 0,68 & 0,81 & 0,84 & 0,91 & 0,92 \\
\hline 30 & 0,79 & 0,74 & 0,43 & 0,50 & 0,46 & 0,59 & 0,63 & 0,65 & 0,75 & 0,78 & 0,86 \\
\hline \multicolumn{12}{|l|}{ P-Valor } \\
\hline “20-10”* & 0,1537 & 0,8085 & 0,6710 & 0,9727 & 0,1432 & 0,9063 & 0,6976 & 0,8293 & 0,9273 & 0,8475 & 0,6237 \\
\hline “30-20”** & 0,0565 & 0,8042 & 0,4087 & 0,6682 & 0,7824 & 0,9939 & 0,3565 & 0,0029 & 0,2030 & 0,0410 & 0,3751 \\
\hline Oonjunta*** & 0,0899 & 0,9257 & 0,5477 & 0,8982 & 0,3419 & 0,9929 & 0,6370 & 0,0113 & 0,4096 & 0,0929 & 0,3816 \\
\hline \multicolumn{12}{|c|}{ Diferença da média condicional dos rendimentos em log entre EM3 e EF8 (Homens Brancos) } \\
\hline experiência & 1992 & 1993 & 1995 & 1996 & 1997 & 1998 & 1999 & 2001 & 2002 & 2003 & 2004 \\
\hline 10 & 0,39 & 0,46 & 0,47 & 0,45 & 0,46 & 0,40 & 0,37 & 0,35 & 0,35 & 0,36 & 0,31 \\
\hline 20 & 0,52 & 0,40 & 0,50 & 0,63 & 0,62 & 0,48 & 0,43 & 0,41 & 0,44 & 0,46 & 0,45 \\
\hline 30 & 0,25 & 0,43 & 0,53 & 0,34 & 0,43 & 0,49 & 0,42 & 0,59 & 0,53 & 0,51 & 0,49 \\
\hline \multicolumn{12}{|l|}{$P$-Valor } \\
\hline "20-10"* & 0,0421 & 4966 & 0,6870 & 0,0011 & ,0001 & 0,1441 & 0,1818 & 0,1174 & 0,0614 & 0,0083 & 0,0155 \\
\hline “30-20”** & 0,0129 & 0,7904 & 0,6700 & 0,0001 & 0,0582 & 0,8641 & 0,7891 & 0,0118 & 0,2193 & 0,3382 & 0,5758 \\
\hline onjunta*** & 0,0334 & 0,7903 & 0,7756 & 0,0001 & 0,0004 & 0,2590 & 0,3977 & 0,0033 & 0,0395 & 0,0018 & 0,0090 \\
\hline \multicolumn{12}{|c|}{ Diferença da média condicional dos rendimentos em log entre EF8 e EF4 (Homens Brancos) } \\
\hline ência & 1992 & 1993 & 1995 & 1996 & 1997 & 1998 & 1999 & 2001 & 2002 & 2003 & 2004 \\
\hline 20 & 0,45 & 0,58 & 0,45 & 0,31 & 0,41 & 0,42 & 0,49 & 0,48 & 0,35 & 0,48 & 0,39 \\
\hline 30 & 0,48 & 0,35 & 0,35 & 0,42 & 0,46 & 0,36 & 0,40 & 0,35 & 0,38 & 0,36 & 0,36 \\
\hline 40 & 0,62 & 0,73 & 0,50 & 0,49 & 0,91 & 0,20 & 0,27 & 0,35 & 0,39 & 0,19 & 0,26 \\
\hline \multicolumn{12}{|l|}{$P$-Valor } \\
\hline “30-20”* & 0,7321 & 0,0085 & 0,0562 & 0,1 &, 5761 & 0,3 & 0,1 & 0,0 & 0,6 & 0,0 & 0,6647 \\
\hline “40-30”** & 0,2295 & 0,0400 & 0,3029 & 0,4865 & 0,0000 & 0,1170 & 0,5485 & 0,9893 & 0,8643 & 0,0002 & 0,4284 \\
\hline Conjunta*** & 0,3241 & 0,0134 & 0,1260 & 0,0545 & 0,0000 & 0,0761 & 0,1951 & 0,2354 & 0,7987 & 0,0000 & 0,4612 \\
\hline \multicolumn{12}{|c|}{ Diferença da média condicional dos rendimentos em log entre EF4 e PRE (Homens Brancos) } \\
\hline Experiência & 1992 & 1993 & 1995 & 1996 & 1997 & 1998 & 1999 & 2001 & 2002 & 2003 & 2004 \\
\hline 20 & 0,32 & 0,45 & 0,64 & 0,23 & 0,18 & 0,46 & 0,43 & 0,34 & 0,32 & 0,06 & 0,35 \\
\hline 30 & 0,58 & 0,70 & 0,42 & 0,59 & & 0,44 & 0,28 & 0,29 & 0,43 & 0,24 & 0,45 \\
\hline 40 & 0,45 & 0,47 & 0,38 & 0,66 & 0,46 & 0,58 & 0,43 & 0,55 & 0,34 & 0,33 & 0,30 \\
\hline \multicolumn{12}{|l|}{ P-Valor } \\
\hline 0 "** & 3 & 0,0409 & 0 , & 54 & & 0 & 0,2 & 0,6760 & 44 & 72 & 0,5857 \\
\hline “40-30”** & 0,3930 & 0,1576 & 0,8339 & 0,6607 & 0,7697 & 0,4235 & 0,3435 & 0,1287 & 0,6361 & 0,5791 & 0,4544 \\
\hline Conjunta*** & 0,3499 & 0,1178 & 0,1802 & 0,0264 & 0,0072 & 0,6768 & 0,5322 & 0,3141 & 0,7817 & 0,0650 & 0,7491 \\
\hline \multicolumn{12}{|c|}{ Diferença da média condicional dos rendimentos em log entre PRE e NEDUC (Homens Brancos) } \\
\hline Experiência & 1992 & 1993 & 1995 & 1996 & 1997 & 1998 & 1999 & 2001 & 2002 & 2003 & 2004 \\
\hline 20 & 0,42 & 0,38 & 0,06 & 0,41 & 0,28 & 0,30 & 0,22 & $-0,20$ & 0,38 & 0,41 & 0,00 \\
\hline 30 & 0,36 & 0,01 & 0,07 & 0,10 & 0,28 & 0,16 & 0,32 & 0,28 & 0,04 & 0,23 & $-0,12$ \\
\hline 40 & 0,28 & 0,36 & 0,28 & $-0,10$ & $-0,10$ & $-0,08$ & 0,12 & 0,00 & 0,23 & 0,22 & 0,10 \\
\hline \multicolumn{12}{|l|}{$P$-Valor } \\
\hline “30-20”* & 0,7841 & 0,0628 & 0,9761 & 0,1083 & 0,9865 & 0,4137 & 0,5873 & 0,0002 & 0,1089 & 0,3326 & 0,6537 \\
\hline “40-30”** & 0,6580 & 0,0569 & 0,3976 & 0,2364 & 0,0130 & 0,2325 & 0,2841 & 0,1405 & 0,4469 & 0,9757 & 0,2758 \\
\hline Conjunta*** & 0,7156 & 0,0725 & 0,5901 & 0,0186 & 0,0093 & 0,0842 & 0,5625 & 0,0007 & 0,2765 & 0,3986 & 0,5518 \\
\hline
\end{tabular}

Nota: SUP4+: nível escolar igual ou acima do superior, EM3: ensino médio, EF8: ginasial, EF4: primário, PRE: pré-escola e NEDUC: sem instrução. Esta nota se aplica para a A-10. 
Tabela A-10 - Diferença da média condicional dos rendimentos em log entre dois grupos de anos de estudo por nível de experiência e P-Valor do teste de paralelismo para três hipóteses nulas.- Censo

\begin{tabular}{|c|c|c|c|c|c|c|c|c|}
\hline \multicolumn{9}{|c|}{ Diferença da média condicional dos rendimentos em log entre (Homens Brancos): } \\
\hline \multirow[b]{2}{*}{ experiência } & \multicolumn{4}{|c|}{ SUP4+ e EM3 } & \multicolumn{4}{|c|}{ EM3 e EF8 } \\
\hline & $1970 * * * *$ & 1980 & 1991 & 2000 & $1970 * * * *$ & 1980 & 1991 & 2000 \\
\hline 10 & 0,95 & 0,99 & 0,88 & 1,03 & 0,52 & 0,52 & 0,43 & 0,39 \\
\hline 20 & 0,74 & 0,72 & 0,79 & 0,93 & 0,46 & 0,51 & 0,51 & 0,48 \\
\hline 30 & 0,53 & 0,55 & 0,65 & 0,85 & 0,45 & 0,47 & 0,50 & 0,51 \\
\hline \multicolumn{9}{|l|}{ P-Valor } \\
\hline “20-10”* & 0,0000 & 0,0000 & 0,0000 & 0,0000 & 0,0000 & 0,1532 & 0,0000 & 0,0000 \\
\hline “30-20”** & 0,0000 & 0,0000 & 0,0000 & 0,0000 & 0,4774 & 0,0027 & 0,6671 & 0,0733 \\
\hline Conjunta*** & 0,0000 & 0,0000 & 0,0000 & 0,0000 & 0,0000 & 0,0000 & 0,0000 & 0,0000 \\
\hline \multicolumn{9}{|c|}{ Diferença da média condicional dos rendimentos em log entre (Homens Brancos): } \\
\hline & \multicolumn{4}{|c|}{ EF8 e EF4 } & \multicolumn{4}{|c|}{ EF4 e NEDUC } \\
\hline experiência & $1970 * * * *$ & 1980 & 1991 & 2000 & $1970 * * * *$ & 1980 & 1991 & 2000 \\
\hline 20 & 0,76 & 0,56 & 0,45 & 0,42 & 0,66 & 0,51 & 0,51 & 0,45 \\
\hline 30 & 0,82 & 0,59 & 0,45 & 0,44 & 0,71 & 0,59 & 0,62 & 0,54 \\
\hline 40 & 0,78 & 0,56 & 0,43 & 0,41 & 0,75 & 0,62 & 0,63 & 0,61 \\
\hline \multicolumn{9}{|l|}{ P-Valor } \\
\hline “30-20”* & 0,0001 & 0,0038 & 0,8269 & 0,1578 & 0,0003 & 0,0000 & 0,0000 & 0,0000 \\
\hline “40-30”** & 0,0232 & 0,0025 & 0,3451 & 0,2425 & 0,0870 & 0,0002 & 0,5734 & 0,0004 \\
\hline Conjunta*** & 0,0004 & 0,0017 & 0,4328 & 0,2794 & 0,0000 & 0,0000 & 0,0000 & 0,0000 \\
\hline
\end{tabular}

**** Para o ano de 1970, não há a variável raça, logo a estimativa é para todos homens. 
Tabela A-11: TIR's - PNADs - Especificação: Anos de Estudo

\begin{tabular}{|c|c|c|c|c|c|c|c|c|c|c|c|c|c|}
\hline \multirow[t]{2}{*}{ Ano } & \multirow[t]{2}{*}{ Método } & \multicolumn{4}{|c|}{ Sem correções } & \multicolumn{4}{|c|}{ Plano Amostral } & \multicolumn{4}{|c|}{ Plano Amostral \& Heckit } \\
\hline & & S4-S0 & S8-S4 & S11-S8 & S15-S11 & S4-S0 & S8-S4 & S11-S8 & S15-S11 & S4-S0 & S8-S4 & S11-S8 & S15-S11 \\
\hline 1992 & 2 Mincer I & 13,1 & 13,1 & 13,1 & 13,1 & 12,8 & 12,8 & 12,8 & 12,8 & 11,8 & 11,8 & 11,8 & 11,8 \\
\hline & Mincer II & 16,2 & 16,2 & 16,2 & 16,2 & 16,0 & 16,0 & 16,0 & 16,0 & 15,4 & 15,4 & 15,4 & 15,4 \\
\hline & TIR-NL & 12,5 & 8,4 & 12,5 & 16,1 & 12,9 & 8,7 & 11,4 & 15,8 & 11,2 & 8,4 & 10,8 & 15,0 \\
\hline & TIR-NPP & 8,3 & 11,2 & 13,9 & 14,3 & 8,6 & 11,2 & 13,5 & 13,7 & 7,8 & 10,3 & 12,7 & 13,0 \\
\hline & TIR-NPNP & 11,9 & 9,3 & 11,2 & 15,9 & 11,9 & 9,3 & 11,2 & 15,6 & - & - & - & - \\
\hline 1993 & 3 Mincer I & 13,9 & 13,9 & 13,9 & 13,9 & 13,5 & 13,5 & 13,5 & 13,5 & 12,7 & 12,7 & 12,7 & 12,7 \\
\hline & Mincer II & 17,2 & 17,2 & 17,2 & 17,2 & 16,9 & 16,9 & 16,9 & 16,9 & 16,4 & 16,4 & 16,4 & 16,4 \\
\hline & TIR-NL & 12,6 & 9,7 & 12,0 & 17,7 & 14,3 & 9,9 & 10,7 & 16,9 & 12,2 & 9,9 & 10,0 & 16,5 \\
\hline & TIR-NPP & 7,8 & 11,5 & 14,8 & 15,7 & 8,7 & 11,6 & 14,3 & 14,6 & 7,6 & 10,7 & 13,5 & 14,2 \\
\hline & TIR-NPNP & 13,6 & 10,4 & 10,8 & 16,6 & 13,6 & 10,3 & 10,8 & 16,5 & - & - & - & - \\
\hline 199 & 5 Mincer I & 14,0 & 14,0 & 14,0 & 14,0 & 13,6 & 13,6 & 13,6 & 13,6 & 12,8 & 12,8 & 12,8 & 12,8 \\
\hline & Mincer II & 17,2 & 17,2 & 17,2 & 17,2 & 16,9 & 16,9 & 16,9 & 16,9 & 16,2 & 16,2 & 16,2 & 16,2 \\
\hline & TIR-NL & 10,3 & 7,6 & 14,6 & 18,5 & 11,0 & 7,5 & 13,8 & 18,5 & 8,9 & 6,9 & 13,7 & 18,3 \\
\hline & TIR-NPP & 6,2 & 10,7 & 14,9 & 16,6 & 6,3 & 10,5 & 14,5 & 16,0 & 4,8 & 9,5 & 13,8 & 15,8 \\
\hline & TIR-NPNP & 11,4 & 7,9 & 13,3 & 19,6 & 11,4 & 7,9 & 13,2 & 19,6 & - & - & - & - \\
\hline 1996 & 5 Mincer I & 13,4 & 13,4 & 13,4 & 13,4 & 13,0 & 13,0 & 13,0 & 13,0 & 12,1 & 12,1 & 12,1 & 12,1 \\
\hline & Mincer II & 16,4 & 16,4 & 16,4 & 16,4 & 16,1 & 16,1 & 16,1 & 16,1 & 15,3 & 15,3 & 15,3 & 15,3 \\
\hline & TIR-NL & 10,5 & 8,0 & 13,7 & 16,5 & 11,7 & 8,1 & 11,9 & 16,3 & 9,5 & 7,6 & 11,2 & 15,9 \\
\hline & TIR-NPP & 6,8 & 10,6 & 14,1 & 15,3 & 7,3 & 10,6 & 13,6 & 14,3 & 6,1 & 9,5 & 12,7 & 13,9 \\
\hline & TIR-NPNP & 10,5 & 8,7 & 11,8 & 16,2 & 10,5 & 8,7 & 11,9 & 16,0 & - & - & - & - \\
\hline 1997 & 7 Mincer I & 13,9 & 13,9 & 13,9 & 13,9 & 13,6 & 13,6 & 13,6 & 13,6 & 12,9 & 12,9 & 12,9 & 12,9 \\
\hline & Mincer II & 16,8 & 16,8 & 16,8 & 16,8 & 16,6 & 16,6 & 16,6 & 16,6 & 15,9 & 15,9 & 15,9 & 15,9 \\
\hline & TIR-NL & 11,4 & 8,4 & 13,9 & 17,1 & 11,2 & 8,6 & 13,8 & 16,4 & 9,1 & 8,3 & 13,0 & 16,0 \\
\hline & TIR-NPP & 6,6 & 10,7 & 14,5 & 15,9 & 6,8 & 10,7 & 14,3 & 15,5 & 5,6 & 9,7 & 13,5 & 15,1 \\
\hline & TIR-NPNP & 9,6 & 9,0 & 13,2 & 17,7 & 9,7 & 8,9 & 13,2 & 17,7 & - & - & - & - \\
\hline 1998 & Mincer I & 13,9 & 13,9 & 13,9 & 13,9 & 13,6 & 13,6 & 13,6 & 13,6 & 13,0 & 13,0 & 13,0 & 13,0 \\
\hline & Mincer II & 16,8 & 16,8 & 16,8 & 16,8 & 16,4 & 16,4 & 16,4 & 16,4 & 15,8 & 15,8 & 15,8 & 15,8 \\
\hline & TIR-NL & 11,2 & 7,3 & 13,5 & 19,3 & 11,7 & 7,3 & 12,8 & 18,7 & 10,2 & 7,0 & 11,8 & 18,5 \\
\hline & TIR-NPP & 5,7 & 10,5 & 14,9 & 16,8 & 6,0 & 10,5 & 14,6 & 16,2 & 5,0 & 9,6 & 13,8 & 15,7 \\
\hline & TIR-NPNP & 11,6 & 7,9 & 12,1 & 19,3 & 11,7 & 8,0 & 12,0 & 19,3 & - & - & - & - \\
\hline
\end{tabular}


Tabela A-11 - Continuação

\begin{tabular}{|c|c|c|c|c|c|c|c|c|c|c|c|c|c|}
\hline & \multirow{2}{*}{$\begin{array}{l}\text { Método } \\
\text { Mincer I }\end{array}$} & \multicolumn{4}{|c|}{ Sem correções } & \multicolumn{4}{|c|}{ Plano Amostral } & \multicolumn{4}{|c|}{ Plano Amostral \& Heckit } \\
\hline & & 13,6 & 13,6 & 13,6 & 13,6 & 13,3 & 13,3 & 13,3 & 13,3 & 12,6 & 12,6 & 12,6 & 12,6 \\
\hline & Mincer II & 16,8 & 16,8 & 16,8 & 16,8 & 16,5 & 16,5 & 16,5 & 16,5 & 15,9 & 15,9 & 15,9 & 15,9 \\
\hline & TIR-NL & 11,4 & 7,6 & 12,5 & 18,9 & 11,5 & 8,3 & 11,3 & 18,1 & 9,6 & 8,2 & 10,8 & 17,2 \\
\hline & TIR-NPP & 5,6 & 10,3 & 14,6 & 16,5 & 6,2 & 10,4 & 14,2 & 15,7 & 5,3 & 9,5 & 13,4 & 15,1 \\
\hline & TIR-NPNP & 12,2 & 8,9 & 10,8 & 18,9 & 12,2 & 8,9 & 10,8 & 18,9 & - & - & - & - \\
\hline 2001 & 1 Mincer I & 13,6 & 13,6 & 13,6 & 13,6 & 13,5 & 13,5 & 13,5 & 13,5 & 12,8 & 12,8 & 12,8 & 12,8 \\
\hline & Mincer II & 16,6 & 16,6 & 16,6 & 16,6 & 16,7 & 16,7 & 16,7 & 16,7 & 16,0 & 16,0 & 16,0 & 16,0 \\
\hline & TIR-NL & 8,8 & 8,7 & 11,2 & 20,7 & 9,2 & 8,4 & 11,6 & 20,5 & 7,4 & 7,4 & 11,0 & 19,9 \\
\hline & TIR-NPP & 4,2 & 9,8 & 15,0 & 17,7 & 4,4 & 9,9 & 15,0 & 17,5 & 3,3 & 8,9 & 14,2 & 16,9 \\
\hline & TIR-NPNP & 7,1 & 9,4 & 10,7 & 21,7 & 7,1 & 9,4 & 10,7 & 21,7 & - & - & - & - \\
\hline 2002 & 2 Mincer I & 13,7 & 13,7 & 13,7 & 13,7 & 13,4 & 13,4 & 13,4 & 13,4 & 12,5 & 12,5 & 12,5 & 12,5 \\
\hline & Mincer II & 16,8 & 16,8 & 16,8 & 16,8 & 16,7 & 16,7 & 16,7 & 16,7 & 15,8 & 15,8 & 15,8 & 15,8 \\
\hline & TIR-NL & 8,5 & 7,2 & 12,2 & 21,8 & 8,8 & 7,3 & 12,1 & 20,8 & 6,2 & 7,0 & 11,4 & 20,2 \\
\hline & TIR-NPP & 2,5 & 8,9 & 15,0 & 18,5 & 2,9 & 8,9 & 14,6 & 17,8 & 1,7 & 8,0 & 13,8 & 17,3 \\
\hline & TIR-NPNP & 8,7 & 7,5 & 11,2 & 21,5 & 8,8 & 7,5 & 11,2 & 21,3 & - & - & - & - \\
\hline 2003 & 3 Mincer I & 13,4 & 13,4 & 13,4 & 13,4 & 13,2 & 13,2 & 13,2 & 13,2 & 12,4 & 12,4 & 12,4 & 12,4 \\
\hline & Mincer II & 16,8 & 16,8 & 16,8 & 16,8 & 16,6 & 16,6 & 16,6 & 16,6 & 15,9 & 15,9 & 15,9 & 15,9 \\
\hline & TIR-NL & 8,5 & 7,1 & 11,7 & 20,3 & 8,5 & 6,8 & 11,8 & 19,8 & 6,9 & 6,3 & 11,2 & 19,1 \\
\hline & TIR-NPP & 2,8 & 8,8 & 14,5 & 17,7 & 2,8 & 8,8 & 14,4 & 17,6 & 2,0 & 8,0 & 13,6 & 16,9 \\
\hline & TIR-NPNP & 7,3 & 8,1 & 10,9 & 20,5 & 7,4 & 8,0 & 10,9 & 20,5 & - & - & - & - \\
\hline 2004 & 4 Mincer I & 13,1 & 13,1 & 13,1 & 13,1 & 12,7 & 12,7 & 12,7 & 12,7 & 11,8 & 11,8 & 11,8 & 11,8 \\
\hline & Mincer II & 16,4 & 16,4 & 16,4 & 16,4 & 16,1 & 16,1 & 16,1 & 16,1 & 15,4 & 15,4 & 15,4 & 15,4 \\
\hline & TIR-NL & 9,7 & 6,9 & 11,2 & 20,8 & 9,0 & 6,7 & 11,3 & 19,6 & 6,9 & 6,4 & 10,8 & 19,0 \\
\hline & TIR-NPP & 2,5 & 8,6 & 14,2 & 17,5 & 2,7 & 8,5 & 13,9 & 17,0 & 1,7 & 7,6 & 13,1 & 16,4 \\
\hline & TIR-NPNP & 8,3 & 6,8 & 10,5 & 19,7 & 8,3 & 6,8 & 10,5 & 19,7 & - & - & - & - \\
\hline
\end{tabular}

${ }^{1}$ Nota: Os valores estão em percentagens. Mincer I e II refere-se aos coeficientes de anos de estudos da regressão minceriana não incluindo e incluindo as variáveis de experiência TIRNL $=$ TIR Não-Linear, TIRNPP $=$ TIR Não Paralelo Paramétrica, TIRNPNP $=$ TIR Não Paralelo Não-Paramétrica (1) = PRE-NEDUC, (2) = EF4-PRE, (3) = EF8-EF4, (4) = EM3-EF8, (5) = SUP-EM3 
Tabela A-12: TIR's - PNADs - Especificação: séries

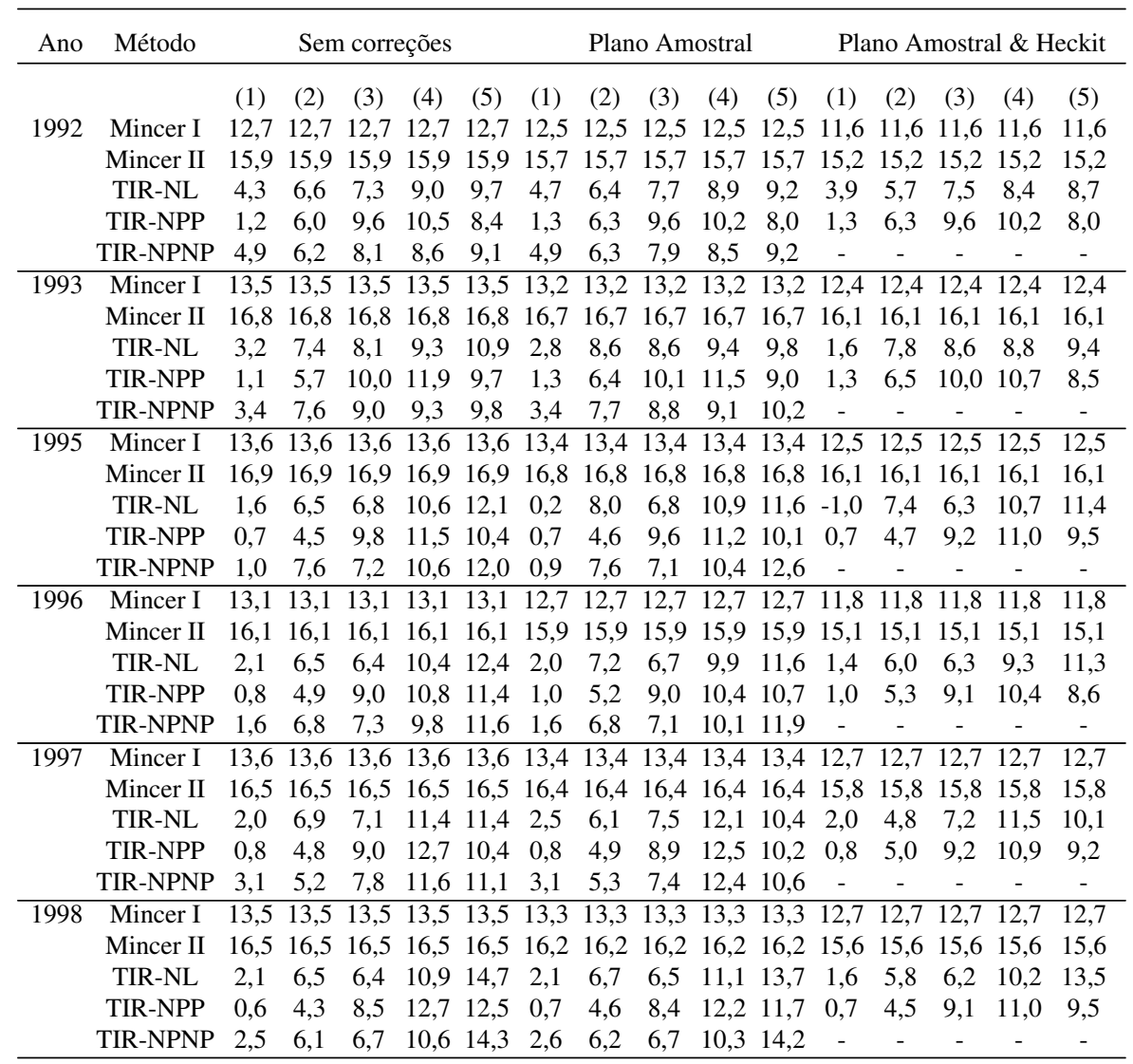


Tabela A-12 - Continuação

\begin{tabular}{|c|c|c|c|c|c|c|c|c|c|c|c|c|c|c|c|c|}
\hline \multirow{2}{*}{$\begin{array}{l}\text { Ano } \\
1999\end{array}$} & \multirow{2}{*}{$\begin{array}{c}\text { Método } \\
\text { Mincer I }\end{array}$} & \multicolumn{6}{|c|}{ Sem correções } & \multicolumn{4}{|c|}{ Plano Amostral } & \multicolumn{5}{|c|}{ Plano Amostral \& Heckit } \\
\hline & & 13,3 & 13,3 & 13,3 & 13,3 & 13,3 & 13,0 & 13,0 & 13,0 & 13,0 & 13,0 & 12,4 & 12,4 & 12,4 & 12,4 & 12,4 \\
\hline & Mincer II & 16,5 & 16,5 & 16,5 & 16,5 & 16,5 & 16,3 & 16,3 & 16,3 & 16,3 & 16,3 & 15,7 & 15,7 & 15,7 & 15,7 & 15,7 \\
\hline & TIR-NL & 2,3 & 7,2 & 6,0 & 10,6 & 12,5 & 2,1 & 7,1 & 6,6 & 10,6 & 11,4 & 1,3 & 6,2 & 6,4 & 10,2 & 10,9 \\
\hline & TIR-NPP & 0,6 & 4,3 & 8,1 & 13,3 & 10,9 & 0,6 & 4,4 & 7,9 & 13,0 & 10,6 & 0,7 & 4,6 & 9,0 & 10,8 & 9,2 \\
\hline & TIR-NPNP & 1,8 & 7,4 & 6,9 & 10,2 & 11,9 & 1,8 & 7,4 & 6,7 & 10,4 & 11,4 & - & - & - & - & - \\
\hline \multirow[t]{5}{*}{2001} & Mincer I & 13,3 & 13,3 & 13,3 & 13,3 & 13,3 & 13,2 & 13,2 & 13,2 & 13,2 & 13,2 & 12,6 & 12,6 & 12,6 & 12,6 & 12,6 \\
\hline & Mincer II & 16,3 & 16,3 & 16,3 & 16,3 & 16,3 & 16,5 & 16,5 & 16,5 & 16,5 & 16,5 & 15,8 & 15,8 & 15,8 & 15,8 & 15,8 \\
\hline & TIR-NL & 2,7 & 5,1 & 7,5 & 7,6 & 15,0 & 3,0 & 4,9 & 7,3 & 8,5 & 14,8 & 2,7 & 4,0 & 6,5 & 8,1 & 13,8 \\
\hline & TIR-NPP & 0,2 & 3,3 & 8,4 & 11,1 & 12,6 & 0,3 & 3,5 & 8,5 & 11,1 & 12,5 & 0,3 & 3,4 & 8,6 & 11,4 & 10,2 \\
\hline & TIR-NPNP & 2,5 & 4,5 & 8,1 & 8,3 & 15,1 & 2,5 & 4,6 & 8,0 & 8,5 & 15,1 & - & - & - & - & - \\
\hline \multirow[t]{5}{*}{2002} & Mincer I & 13,4 & 13,4 & 13,4 & 13,4 & 13,4 & 13,2 & 13,2 & 13,2 & 13,2 & 13,2 & 12,3 & 12,3 & 12,3 & 12,3 & 12,3 \\
\hline & Mincer II & 16,6 & 16,6 & 16,6 & 16,6 & 16,6 & 16,5 & 16,5 & 16,5 & 16,5 & 16,5 & 15,7 & 15,7 & 15,7 & 15,7 & 15,7 \\
\hline & TIR-NL & 0,3 & 6,6 & 6,0 & 8,9 & 14,8 & $-0,6$ & 6,9 & 6,2 & 9,6 & 13,5 & $-1,6$ & 5,7 & 5,9 & 9,0 & 13,0 \\
\hline & TIR-NPP & $-0,1$ & 2,1 & 7,6 & 12,0 & 12,5 & 0,0 & 2,4 & 7,5 & 11,7 & 12,1 & 0,0 & 2,3 & 7,8 & 11,1 & 10,5 \\
\hline & TIR-NPNP & $-1,3$ & 7,1 & 6,3 & 9,2 & 13,9 & $-1,3$ & 7,2 & 6,4 & 9,0 & 13,8 & - & - & - & - & - \\
\hline \multirow[t]{5}{*}{2003} & Mincer I & 13,1 & 13,1 & 13,1 & 13,1 & 13,1 & 13,0 & 13,0 & 13,0 & 13,0 & 13,0 & 12,2 & 12,2 & 12,2 & 12,2 & 12,2 \\
\hline & Mincer II & 16,5 & 16,5 & 16,5 & 16,5 & 16,5 & 16,4 & 16,4 & 16,4 & 16,4 & 16,4 & 15,7 & 15,7 & 15,7 & 15,7 & 15,7 \\
\hline & TIR-NL & 2,9 & 5,0 & 6,1 & 8,1 & 13,6 & 3,0 & 4,4 & 6,0 & 8,9 & 12,7 & 2,4 & 3,5 & 5,6 & 8,5 & 12,2 \\
\hline & TIR-NPP & 0,0 & 2,4 & 8,0 & 10,7 & 11,7 & 0,0 & 2,3 & 7,9 & 10,6 & 11,6 & 0,0 & 2,4 & 7,7 & 10,9 & 10,2 \\
\hline & TIR-NPNP & 3,5 & 3,9 & 7,0 & 8,6 & 13,2 & 3,5 & 4,0 & 7,1 & 8,6 & 12,7 & - & - & - & - & - \\
\hline \multirow[t]{5}{*}{2004} & Mincer I & 12,8 & 12,8 & 12,8 & 12,8 & 12,8 & 12,5 & 12,5 & 12,5 & 12,5 & 12,5 & 11,6 & 11,6 & 11,6 & 11,6 & 11,6 \\
\hline & Mincer II & 16,2 & 16,2 & 16,2 & 16,2 & 16,2 & 16,0 & 16,0 & 16,0 & 16,0 & 16,0 & 15,3 & 15,3 & 15,3 & 15,3 & 15,3 \\
\hline & TIR-NL & 1,3 & 7,0 & 5,6 & 7,9 & 12,6 & 1,4 & 6,1 & 5,7 & 8,8 & 11,5 & 1,0 & 4,7 & 5,5 & 8,3 & 11,1 \\
\hline & TIR-NPP & $-0,1$ & 2,2 & 7,3 & 10,7 & 10,8 & 0,0 & 2,3 & 7,2 & 10,5 & 10,4 & 0,0 & 2,2 & 7,4 & 10,6 & 10,0 \\
\hline & TIR-NPNP & 1,1 & 6,0 & 5,8 & 8,4 & 11,6 & 0,9 & 6,1 & 5,7 & 8,2 & 12,4 & - & - & - & - & - \\
\hline
\end{tabular}

${ }^{1}$ Nota: Os valores estão em percentagens. Mincer I e II refere-se aos coeficientes de anos de estudos da regressão minceriana não incluindo e incluindo as variáveis de experiência TIRNL $=$ TIR Não-Linear, TIRNPP $=$ TIR Não Paralelo Paramétrica, TIRNPNP $=$ TIR Não Paralelo Não-Paramétrica (1) = PRE-NEDUC, (2) = EF4-PRE, (3) = EF8-EF4, (4) = EM3-EF8, (5) = SUP-EM3 

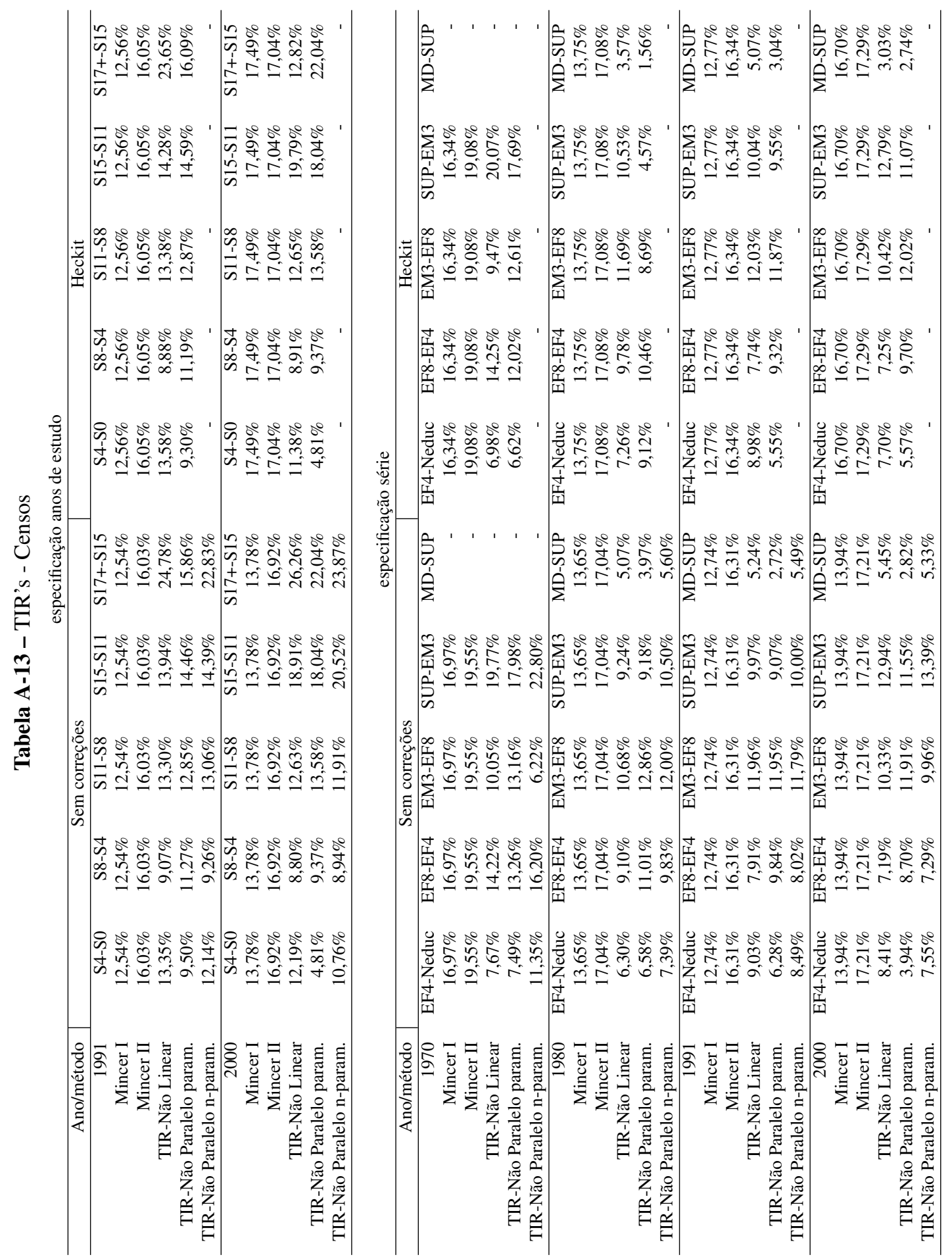
Não Paramétrico - Plano Amostral

\begin{tabular}{|c|c|c|c|c|c|c|c|c|c|}
\hline \multirow{2}{*}{$\begin{array}{c}\text { Ano/método } \\
1992\end{array}$} & \multicolumn{4}{|c|}{ especificação anos de estudo } & \multicolumn{5}{|c|}{ especificação série } \\
\hline & -So & -S4 & S8 & 11 & 1 & EF4- & 50 & EM3-EF8 & SUP \\
\hline TIR - Não Paralelo & $11,91 \%$ & $9,33 \%$ & $11,19 \%$ & $15,64 \%$ & $4,95 \%$ & $6,31 \%$ & $7,86 \%$ & & \\
\hline TIR - adicional1 & $11,65 \%$ & $7,78 \%$ & $13,47 \%$ & $16,85 \%$ & $3,44 \%$ & $6,23 \%$ & $6,83 \%$ & $10,32 \%$ & \\
\hline TIR - adici & $8,09 \%$ & $19,52 \%$ & $14,66 \%$ & $28,39 \%$ & $1,23 \%$ & $5,34 \%$ & $14,97 \%$ & $11,36 \%$ & $4 \%$ \\
\hline TIR - adici & $8,32 \%$ & $19,48 \%$ & $14,59 \%$ & $28,39 \%$ & $1,61 \%$ & $5,66 \%$ & $14,89 \%$ & $11,18 \%$ & $15,79 \%$ \\
\hline TIR - adicional4 & $7,12 \%$ & $13,87 \%$ & $12,88 \%$ & $21,91 \%$ & $1,19 \%$ & $4,83 \%$ & $11,47 \%$ & $10,16 \%$ & $12,01 \%$ \\
\hline 1993 & S4-S0 & S8-S4 & S11-S8 & S15-S11 & PRE-NEDUC & EF4-PRE & EF8-EF4 & 4 EM3-EF8 & SUP-EM3 \\
\hline TIR - Não Pa & $13,62 \%$ & $10,34 \%$ & $10,82 \%$ & $16,52 \%$ & & & & & \\
\hline TIR - adic & $12,43 \%$ & $9,15 \%$ & $13,38 \%$ & $17,52 \%$ & & & & & \\
\hline TIR & $\%$ & $17,14 \%$ & $21,32 \%$ & $18,66 \%$ & & 6 & $\%$ & & \\
\hline TIR & $9,88 \%$ & $17,06 \%$ & $21,31 \%$ & $18,65 \%$ & & 7,0 & $\%$ & & \\
\hline TIR - adi & $8,30 \%$ & $12,61 \%$ & $17,85 \%$ & $15,68 \%$ & $-0,07 \%$ & $6,02 \%$ & $10,48 \%$ & $3 \%$ & $9 \%$ \\
\hline 19 & & & & & E-NEDL & $\overline{\mathrm{EF} 4-\mathrm{PRE}}$ & 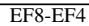 & EM & \\
\hline TIR - Não & $11,37 \%$ & $7,94 \%$ & $13,23 \%$ & $19,59 \%$ & & $7,57 \%$ & & & \\
\hline TIR - adic & $12,14 \%$ & $8,69 \%$ & $12,32 \%$ & 19,7 & & & & & \\
\hline TIR & $9,12 \%$ & $13,90 \%$ & $16,37 \%$ & 25,6 & & & & & \\
\hline TIR - & $9,42 \%$ & $13,79 \%$ & $16,35 \%$ & $25,64 \%$ & & & & & \\
\hline TIR - adici & $7,97 \%$ & $11,16 \%$ & $13,92 \%$ & $20,29 \%$ & $0,61 \%$ & $5,71 \%$ & $10,03 \%$ & $11,12 \%$ & $12,61 \%$ \\
\hline 1996 & S4-S0 & S8-S4 & & S15-S11 & PRE-NEDUC & EF4-PRE & EF8-EF4 & EM3-EF8 & SUP-EM3 \\
\hline TIR - Não Pa & $10,54 \%$ & $8,71 \%$ & & $15,99 \%$ & & & & & \\
\hline TIR - adici & $10,86 \%$ & $8,91 \%$ & $11,80 \%$ & $16,91 \%$ & & & & & \\
\hline & & $\%$ & & & & & & & \\
\hline & $\%$ & $\%$ & 15 , & 21,1 & & & & & \\
\hline TIF & $\%$ & $11,06 \%$ & $13,46 \%$ & 16 & & & & & \\
\hline TIR - adiciona & $5,76 \%$ & $9,87 \%$ & $12,21 \%$ & $17,33 \%$ & $0,92 \%$ & $4,14 \%$ & $8,42 \%$ & $5 \%$ & $2 \%$ \\
\hline & S4-S0 & S8-S4 & & & PRE-NEDUC & EF4-PRE & EF8-EF4 & EM3 & SUP-EM3 \\
\hline TIR - Não & $9,65 \%$ & $8,94 \%$ & $13,22 \%$ & $17,66 \%$ & & $5,27 \%$ & $7,42 \%$ & 12,4 & \\
\hline TIR - adi & $9,86 \%$ & $9,43 \%$ & $11,77 \%$ & $17,89 \%$ & & $5,79 \%$ & $7,89 \%$ & 10 , & \\
\hline TIR - adicional2 & $5,83 \%$ & $13,92 \%$ & $18,41 \%$ & $17,68 \%$ & $1,60 \%$ & $3,67 \%$ & $11,02 \%$ & $16,12 \%$ & $13,11 \%$ \\
\hline TIR - adicional3 & $6,46 \%$ & $13,87 \%$ & $18,38 \%$ & $17,67 \%$ & $2,25 \%$ & $4,38 \%$ & $10,93 \%$ & $16,06 \%$ & $13,06 \%$ \\
\hline TIR - adicional 4 & $5,81 \%$ & $11,11 \%$ & $15,68 \%$ & $14,89 \%$ & $1,68 \%$ & $3,93 \%$ & $9,20 \%$ & $14,00 \%$ & $10,69 \%$ \\
\hline 1998 & S4-S0 & S8-S4 & S11-S8 & S15-S11 & PRE-NEDUC & EF4-PRE & EF8-EF4 & EM3-EF8 & SUP-EM3 \\
\hline TIR - Não Paralelo & $11,71 \%$ & $7,99 \%$ & $12,02 \%$ & $19,30 \%$ & $2,59 \%$ & $6,19 \%$ & $6,68 \%$ & $10,28 \%$ & $14,19 \%$ \\
\hline TIR - adicio & $9,16 \%$ & $8,45 \%$ & $12,33 \%$ & $18,78 \%$ & $2,89 \%$ & $5,04 \%$ & $6,76 \%$ & $10,76 \%$ & $14,58 \%$ \\
\hline TIR - adi & $6,21 \%$ & $12,91 \%$ & $17,12 \%$ & $22,93 \%$ & & 3,7 & $9,88 \%$ & 14, & $16,96 \%$ \\
\hline TIR - adici & $6,86 \%$ & $12,73 \%$ & $17,10 \%$ & $22,93 \%$ & $1,78 \%$ & $4,51 \%$ & $9,55 \%$ & $14,16 \%$ & $16,95 \%$ \\
\hline TIR - adicional4 & $6,03 \%$ & $10,19 \%$ & $14,45 \%$ & $18,36 \%$ & $1,29 \%$ & $3,97 \%$ & $7,72 \%$ & $12,38 \%$ & $13,15 \%$ \\
\hline
\end{tabular}


Tabela A-14 - Continuação

\begin{tabular}{|c|c|c|c|c|c|c|c|c|c|}
\hline \multirow{2}{*}{$\begin{array}{c}\text { Ano/método } \\
1999\end{array}$} & \multicolumn{4}{|c|}{ especificação anos de estudo } & \multicolumn{5}{|c|}{ especificação série } \\
\hline & S4-S0 & S8-S4 & S11-S8 & $\mathrm{S} 15$ & PRE-NED & EF4-PRE & EF8-EF4 & EM3-EF8 & SUP-EM3 \\
\hline TIR - Não Paralelo & $12,18 \%$ & $8,90 \%$ & $10,76 \%$ & $18,92 \%$ & $1,85 \%$ & $7,42 \%$ & $6,68 \%$ & & \\
\hline TIR - adicional 1 & $9,64 \%$ & $8,34 \%$ & $12,03 \%$ & $19,16 \%$ & & $5,63 \%$ & $6,37 \%$ & $0 \%$ & $3 \%$ \\
\hline TIR - adicional2 & $6,58 \%$ & $10,01 \%$ & $20,39 \%$ & $23,35 \%$ & $1,04 \%$ & $3,87 \%$ & $7,77 \%$ & $18,67 \%$ & $15,90 \%$ \\
\hline TIR - adicional 3 & $7,28 \%$ & $9,86 \%$ & $20,37 \%$ & $23,34 \%$ & $1,69 \%$ & $4,90 \%$ & $7,49 \%$ & $18,64 \%$ & $15,87 \%$ \\
\hline TIR - adicional4 & $6,37 \%$ & $8,37 \%$ & $17,25 \%$ & $18,36 \%$ & $1,28 \%$ & $4,32 \%$ & $6,32 \%$ & $16,04 \%$ & $12,34 \%$ \\
\hline 2001 & S4-S0 & S8-S4 & S11-S8 & S15-S11 & PRE-NEDUC & EF4-PRE & EF8-EF4 & EM3-EF8 & SUP-EM3 \\
\hline TIR - Não Pa & $7,11 \%$ & $9,42 \%$ & $10,72 \%$ & $21,68 \%$ & $2,47 \%$ & $4,55 \%$ & & & $3 \%$ \\
\hline TIR - ad & $7,69 \%$ & $8,64 \%$ & $10,95 \%$ & $21,93 \%$ & & $4,88 \%$ & & & \\
\hline TIR - & $7,25 \%$ & $12,32 \%$ & $13,49 \%$ & $27,47 \%$ & & $4,61 \%$ & $\%$ & & $\%$ \\
\hline TIR - & $7,58 \%$ & $12,21 \%$ & $13,48 \%$ & $27,47 \%$ & & $4,99 \%$ & & $3 \%$ & $9 \%$ \\
\hline TIR - adicior & $6,47 \%$ & $9,91 \%$ & $11,93 \%$ & $21,55 \%$ & $1,40 \%$ & $4,28 \%$ & & $8,87 \%$ & $13,43 \%$ \\
\hline 2002 & 4-S0 & S8-S4 & S11-S8 & S15-S11 & E-NEDL & 4-PRE & EF8-EF4 & EM3-EF8 & EM3 \\
\hline TIR - Não Pc & $8,76 \%$ & $7,52 \%$ & $11,19 \%$ & $21,33 \%$ & $-1,34 \%$ & $7,23 \%$ & $6,37 \%$ & $9,04 \%$ & $2 \%$ \\
\hline TIR - adicional1 & $8,74 \%$ & $6,64 \%$ & $11,72 \%$ & $22,44 \%$ & $0,46 \%$ & $6,51 \%$ & & & $9 \%$ \\
\hline TIR - adicional2 & $5,20 \%$ & $10,13 \%$ & $17,05 \%$ & $24,84 \%$ & $-1,10 \%$ & $4,12 \%$ & & $9 \%$ & $78 \%$ \\
\hline TIR - adicional3 & $5,81 \%$ & $9,90 \%$ & $17,04 \%$ & $24,83 \%$ & & & & & $16,75 \%$ \\
\hline TIR - adicior & $5,18 \%$ & $7,93 \%$ & $14,59 \%$ & $19,72 \%$ & $0,81 \%$ & $4,06 \%$ & $6,54 \%$ & $11,81 \%$ & $13,08 \%$ \\
\hline 2003 & S4-S0 & S8-S4 & S11-S8 & S15-S11 & PRE-NEDUC & EF4-PRE & EF8-EF4 & EM3-EF8 & SUP-EM3 \\
\hline TIR - Não Pa & $7,36 \%$ & $8,02 \%$ & $10,87 \%$ & $20,51 \%$ & & $3,98 \%$ & & & $67 \%$ \\
\hline TIR - ad & $7,28 \%$ & $7,35 \%$ & $10,93 \%$ & $20,50 \%$ & & $5 \%$ & & & \\
\hline TIR - & $3,74 \%$ & $14,33 \%$ & $19,18 \%$ & $23,08 \%$ & & $2,24 \%$ & $\%$ & $\%$ & \\
\hline TIR - ad & $4,69 \%$ & $14,16 \%$ & $19,16 \%$ & $23,08 \%$ & 7 & $3,39 \%$ & $11,64 \%$ & $3 \%$ & $1 \%$ \\
\hline TIR - adicional 4 & $4,23 \%$ & $10,82 \%$ & $16,32 \%$ & $18,93 \%$ & $1,13 \%$ & $3,06 \%$ & $9,29 \%$ & $11,25 \%$ & $13,31 \%$ \\
\hline 2004 & S4-S0 & S8-S4 & S11-S8 & S15-S11 & PRE-NEDUC & EF4-PRE & EF8-EF4 & EM3-EF8 & SUP-EM3 \\
\hline TIR - Não Pa & $8,27 \%$ & $6,78 \%$ & $10,50 \%$ & $19,66 \%$ & $0,93 \%$ & $6,13 \%$ & $5,70 \%$ & $8,20 \%$ & $12,38 \%$ \\
\hline TIR - adic & $8,53 \%$ & $6,43 \%$ & $10,81 \%$ & $20,88 \%$ & & $6,41 \%$ & $5,39 \%$ & & $12,56 \%$ \\
\hline TIR - ad & $2,94 \%$ & $15,63 \%$ & $13,15 \%$ & $23,59 \%$ & $0,49 \%$ & $2,08 \%$ & $12,24 \%$ & $9,92 \%$ & $14,61 \%$ \\
\hline TIR - adicional3 & $4,44 \%$ & $15,51 \%$ & $13,16 \%$ & $23,59 \%$ & $1,32 \%$ & $3,50 \%$ & $11,93 \%$ & $9,92 \%$ & $14,57 \%$ \\
\hline TIR - adicional4 & $4,06 \%$ & $12,01 \%$ & $11,78 \%$ & $19,05 \%$ & $0,99 \%$ & $3,14 \%$ & $9,60 \%$ & $9,17 \%$ & $11,45 \%$ \\
\hline
\end{tabular}

${ }^{1}$ Nota: Adicional 1: TIR não linear ou não paralela, mas foi incluído os que estudam enquanto trabalham. Adicional 2: Adicional 1 com faixa etária de 10 a 65 anos e $l=40$ primeiros anos $\left(l^{\prime}(s)=1\right)$. Adicional 3: Adicional 1 com faixa etária de 10 a 65 anos e idade de aposentadoria igual a $65\left(l^{\prime}(s)=0\right)$. Adicional 4: Adicional 3 e incluído os custos diretos. Esta nota se aplica às Tabelas A-15-A-17. 
Não Linear - Plano Amostral \& Heckit

\begin{tabular}{|c|c|c|c|c|c|c|c|c|c|}
\hline \multirow{2}{*}{$\begin{array}{c}\text { Ano/método } \\
1992\end{array}$} & \multicolumn{4}{|c|}{ especificação anos de estudo } & \multicolumn{5}{|c|}{ especificação série } \\
\hline & S4-S0 & S8-S4 & S11-S8 & S15-S11 & PRE-NEDUC & EF4-PRE & EF8-EF4 & EM3-EF8 & SUP-EM3 \\
\hline TIR - Não Linear & 11,22 & 8,42 & 10,77 & 15,02 & 3,87 & 5,72 & 7,51 & 8,43 & 8,67 \\
\hline TIR - adicional1 & 11,12 & 7,68 & 13,28 & 16,46 & 3,05 & 5,88 & 6,59 & 10,03 & 9,31 \\
\hline TIR - adicional2 & 9,31 & 8,40 & 16,39 & 20,02 & 1,94 & 5,23 & 7,12 & 12,14 & 11,11 \\
\hline TIR - adicional3 & 9,38 & 8,27 & 16,37 & 20,01 & 2,01 & 5,38 & 6,94 & 12,08 & 11,03 \\
\hline TIR - adicional4 & 8,09 & 7,28 & 14,70 & 17,18 & 1,55 & 4,72 & 6,24 & 11,17 & 9,32 \\
\hline 1993 & S4-S0 & S8-S4 & S11-S8 & S15-S11 & PRE-NEDUC & EF4-PRE & EF8-EF4 & EM3-EF8 & SUP-EM3 \\
\hline TIR - Não Linear & 12,18 & 9,90 & 9,99 & 16,46 & 1,60 & 7,78 & 8,60 & 8,78 & 9,41 \\
\hline TIR - adicional1 & 12,79 & 8,74 & 12,85 & 17,80 & 1,80 & 7,79 & 7,28 & 10,66 & 10,98 \\
\hline TIR - adicional2 & 11,70 & 9,53 & 16,21 & 21,21 & 1,26 & 7,15 & 7,93 & 13,21 & 12,46 \\
\hline TIR - adicional3 & 11,74 & 9,44 & 16,20 & 21,21 & 1,34 & 7,25 & 7,78 & 13,17 & 12,42 \\
\hline TIR - adicional 4 & 9,93 & 8,29 & 14,59 & 18,08 & 0,89 & 6,30 & 6,97 & 12,14 & 10,55 \\
\hline 1995 & S4-S0 & S8-S4 & S11-S8 & S15-S11 & PRE-NEDUC & EF4-PRE & EF8-EF4 & EM3-EF8 & SUP-EM3 \\
\hline TIR - Não Linear & 8,89 & 6,88 & 13,66 & 18,29 & $-0,98$ & 7,36 & 6,27 & 10,74 & 11,36 \\
\hline TIR - adicional1 & 11,63 & 8,02 & 12,50 & 19,32 & 0,56 & 7,98 & 6,96 & 9,77 & 12,49 \\
\hline TIR - adicional2 & 10,04 & 8,99 & 15,69 & 25,38 & 0,84 & 6,59 & 7,89 & 12,02 & 14,98 \\
\hline TIR - adicional3 & 10,13 & 8,89 & 15,67 & 23,44 & 0,94 & 6,73 & 7,76 & 11,95 & 14,95 \\
\hline TIR - adicional4 & 8,67 & 7,78 & 13,97 & 19,59 & 0,57 & 5,89 & 6,88 & 10,98 & 12,45 \\
\hline 1996 & S4-S0 & S8-S4 & S11-S8 & S15-S11 & PRE-NEDUC & EF4-PRE & EF8-EF4 & EM3-EF8 & SUP-EM3 \\
\hline TIR - Não Linear & 9,54 & 7,64 & 11,19 & 15,88 & 1,36 & 6,03 & 6,30 & 9,32 & 11,29 \\
\hline TIR - adicional1 & 9,80 & 8,34 & 11,62 & 17,69 & 1,37 & 6,23 & 6,85 & 9,46 & 13,40 \\
\hline TIR - adicional2 & 9,02 & 8,86 & 14,83 & 21,58 & 1,90 & 5,23 & 7,20 & 11,90 & 15,54 \\
\hline TIR - adicional3 & 9,12 & 8,76 & 14,80 & 21,58 & 1,98 & 5,41 & 7,03 & 11,84 & 15,52 \\
\hline TIR - adicional 4 & 7,95 & 7,61 & 13,20 & 18,05 & 1,48 & 4,81 & 6,25 & 10,83 & 13,03 \\
\hline TIR - adicional4 (POF) & ) 7,06 & 7,07 & 12,25 & 18,42 & 1,47 & 4,31 & 5,87 & 10,20 & 13,29 \\
\hline 1997 & S4-S0 & S8-S4 & S11-S8 & S15-S11 & PRE-NEDUC & EF4-PRE & EF8-EF4 & EM3-EF8 & SUP-EM3 \\
\hline TIR - Não Linear & 9,07 & 8,28 & 13,00 & 15,99 & 2,01 & 4,83 & 7,25 & 11,47 & 10,09 \\
\hline TIR - adicional1 & 9,88 & 8,68 & 12,28 & 17,67 & 2,92 & 5,19 & 6,99 & 11,64 & 10,73 \\
\hline TIR - adicional2 & 8,77 & 9,18 & 15,17 & 21,44 & 2,69 & 4,55 & 7,36 & 14,50 & 12,40 \\
\hline TIR - adicional3 & 8,89 & 9,09 & 15,15 & 21,43 & 2,77 & 4,77 & 7,21 & 14,47 & 12,36 \\
\hline TIR - adicional 4 & 7,72 & 8,02 & 13,48 & 18,16 & 2,15 & 4,22 & 6,33 & 12,97 & 10,27 \\
\hline 1998 & S4-S0 & S8-S4 & S11-S8 & S15-S11 & PRE-NEDUC & EF4-PRE & EF8-EF4 & EM3-EF8 & SUP-EM3 \\
\hline TIR - Não Linear & 10,20 & 6,99 & 11,76 & 18,49 & 1,64 & 5,83 & 6,24 & 10,25 & 13,48 \\
\hline TIR - adicional 1 & 9,18 & 7,85 & 11,99 & 19,51 & 1,39 & 5,70 & 6,36 & 10,16 & 14,29 \\
\hline TIR - adicional2 & 8,14 & 8,25 & 15,43 & 23,40 & 1,00 & 5,18 & 6,66 & 12,87 & 16,26 \\
\hline TIR - adicional3 & 8,28 & 8,13 & 15,40 & 23,40 & 1,10 & 5,38 & 6,47 & 12,82 & 16,25 \\
\hline TIR - adicional 4 & 7,16 & 7,14 & 13,68 & 19,47 & 0,71 & 4,70 & 5,66 & 11,64 & 13,23 \\
\hline
\end{tabular}


Tabela A-15 - Continuação

\begin{tabular}{|c|c|c|c|c|c|c|c|c|c|}
\hline \multirow{2}{*}{$\begin{array}{c}\text { Ano/método } \\
1999\end{array}$} & \multicolumn{4}{|c|}{ especificação anos de estudo } & \multicolumn{5}{|c|}{ especificação série } \\
\hline & S4-S0 & S8-S4 & S11-S8 & S15-S11 & PRE-NEDUC & EF4-PRE & EF8-EF4 & EM3-EF8 & SUP-EM3 \\
\hline TIR - Não Linear & 9,56 & 8,24 & 10,82 & 17,25 & 1,33 & 6,23 & 6,43 & 10,19 & 10,91 \\
\hline TIR - adicional1 & 10,37 & 7,79 & 12,11 & 18,70 & 2,27 & 6,21 & 6,02 & 10,38 & 13,57 \\
\hline TIR - adicional2 & 9,24 & 8,38 & 14,77 & 22,82 & 2,03 & 5,52 & 6,18 & 14,21 & 13,90 \\
\hline TIR - adicional3 & 9,36 & 8,28 & 14,75 & 22,82 & 2,13 & 5,73 & 5,99 & 14,17 & 13,86 \\
\hline TIR - adicional4 & 8,06 & 7,24 & 13,22 & 18,65 & 1,57 & 5,02 & 5,24 & 12,79 & 11,07 \\
\hline 2001 & S4-S0 & S8-S4 & S11-S8 & S15-S11 & PRE-NEDUC & EF4-PRE & EF8-EF4 & EM3-EF8 & SUP-EM3 \\
\hline TIR - Não Linear & 7,45 & 7,41 & 11,04 & 19,94 & 2,66 & 3,99 & 6,46 & 8,11 & 13,83 \\
\hline TIR - adicional1 & 7,82 & 7,65 & 11,61 & 20,65 & 2,13 & 4,73 & 6,44 & 8,90 & 14,50 \\
\hline TIR - adicional2 & 7,36 & 8,39 & 13,96 & 24,45 & 1,65 & 4,60 & 7,03 & 10,58 & 16,96 \\
\hline TIR - adicional3 & 7,52 & 8,27 & 13,92 & 24,45 & 1,73 & 4,81 & 6,85 & 10,48 & 16,95 \\
\hline TIR - adicional4 & 6,50 & 7,26 & 12,50 & 20,11 & 1,29 & 4,20 & 6,14 & 9,67 & 13,64 \\
\hline 2002 & S4-S0 & S8-S4 & S11-S8 & S15-S11 & PRE-NEDUC & EF4-PRE & EF8-EF4 & EM3-EF8 & SUP-EM3 \\
\hline TIR - Não Linear & 6,21 & 7,01 & 11,40 & 20,20 & $-1,62$ & 5,72 & 5,90 & 9,05 & 12,99 \\
\hline TIR - adicional1 & 8,42 & 6,02 & 12,61 & 22,00 & $-0,25$ & 6,77 & 5,19 & 9,87 & 14,18 \\
\hline TIR - adicional2 & 7,96 & 6,75 & 14,69 & 25,61 & 0,02 & 5,96 & 5,82 & 11,42 & 16,44 \\
\hline TIR - adicional3 & 8,09 & 6,50 & 14,66 & 25,61 & 0,12 & 6,11 & 5,52 & 11,34 & 16,43 \\
\hline TIR - adicional4 & 7,00 & 5,67 & 13,08 & 20,98 & $-0,16$ & 5,31 & 4,91 & 10,39 & 13,31 \\
\hline 2003 & S4-S0 & S8-S4 & S11-S8 & S15-S11 & PRE-NEDUC & EF4-PRE & EF8-EF4 & EM3-EF8 & SUP-EM3 \\
\hline TIR - Não Linear & 6,91 & 6,33 & 11,23 & 19,05 & 2,40 & 3,53 & 5,56 & 8,50 & 12,21 \\
\hline TIR - adicional1 & 7,75 & 6,17 & 11,36 & 21,00 & 0,53 & 5,49 & 5,58 & 8,63 & 13,06 \\
\hline TIR - adicional2 & 7,56 & 6,99 & 13,43 & 25,02 & 0,41 & 5,38 & 6,39 & 9,90 & 15,40 \\
\hline TIR - adicional3 & 7,71 & 6,76 & 13,38 & 25,02 & 0,51 & 5,55 & 6,14 & 9,77 & 15,38 \\
\hline TIR - adicional4 & 6,65 & 5,98 & 12,07 & 20,91 & 0,20 & 4,82 & 5,49 & 8,78 & $12,55 \%$ \\
\hline 2004 & S4-S0 & S8-S4 & S11-S8 & S15-S11 & PRE-NEDUC & EF4-PRE & EF8-EF4 & EM3-EF8 & SUP-EM3 \\
\hline TIR - Não Linear & 6,94 & 6,35 & 10,77 & 19,01 & 0,95 & 4,73 & 5,47 & 8,34 & 11,14 \\
\hline TIR - adicional1 & 8,26 & 5,30 & 11,48 & 21,06 & 0,89 & 5,83 & 4,64 & 8,58 & 13,18 \\
\hline TIR - adicional2 & 7,74 & 6,41 & 13,61 & 24,76 & 1,18 & 5,05 & 5,48 & 9,94 & 15,27 \\
\hline TIR - adicional3 & 7,87 & 6,14 & 13,56 & 24,76 & 1,26 & 5,24 & 5,16 & 9,82 & 15,25 \\
\hline TIR - adicional4 & 6,79 & 5,38 & 12,24 & 20,42 & 0,90 & 4,53 & 4,61 & 8,83 & 12,53 \\
\hline
\end{tabular}

${ }^{1}$ Nota: Os valores estão em percentagens. 


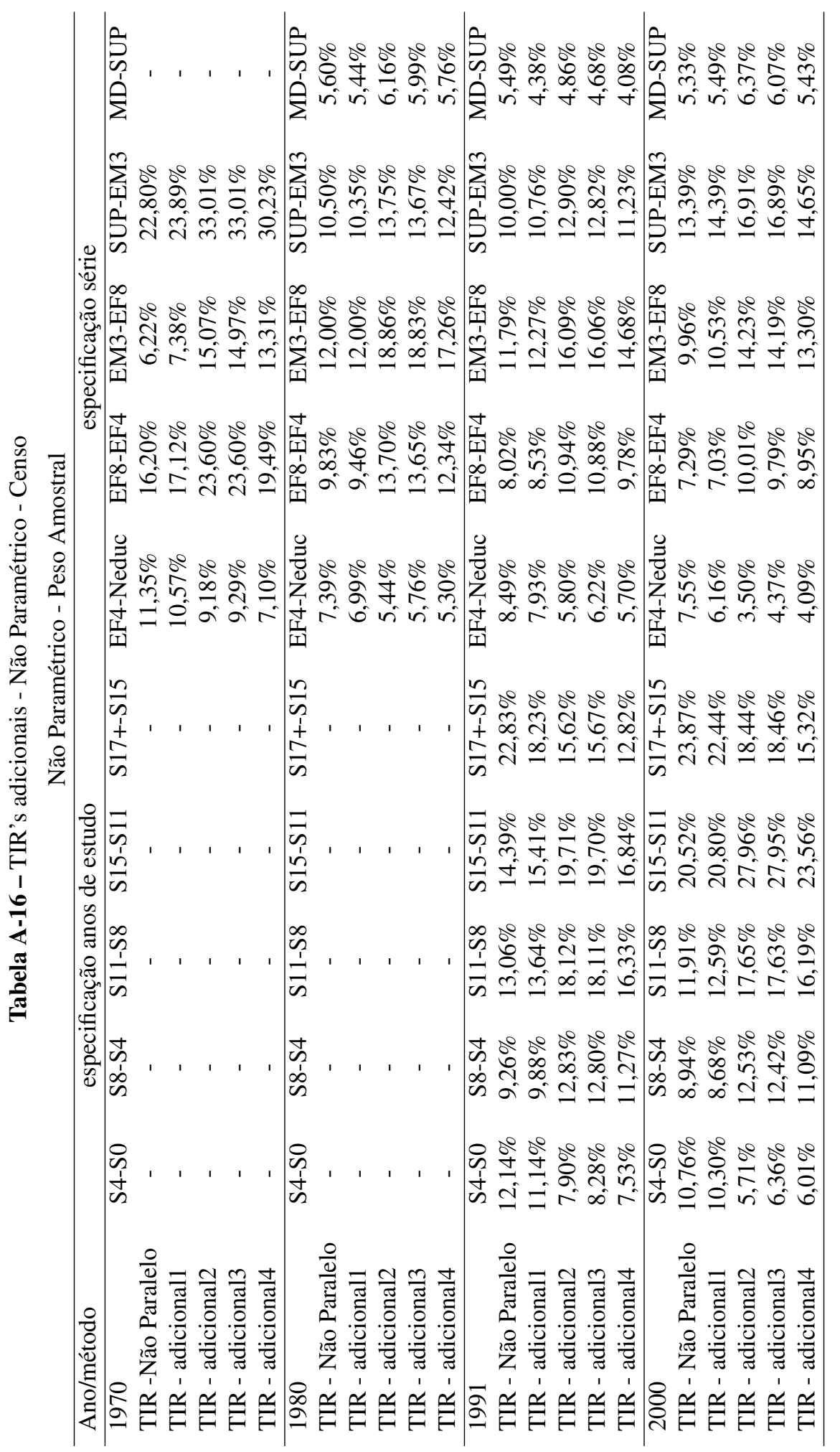




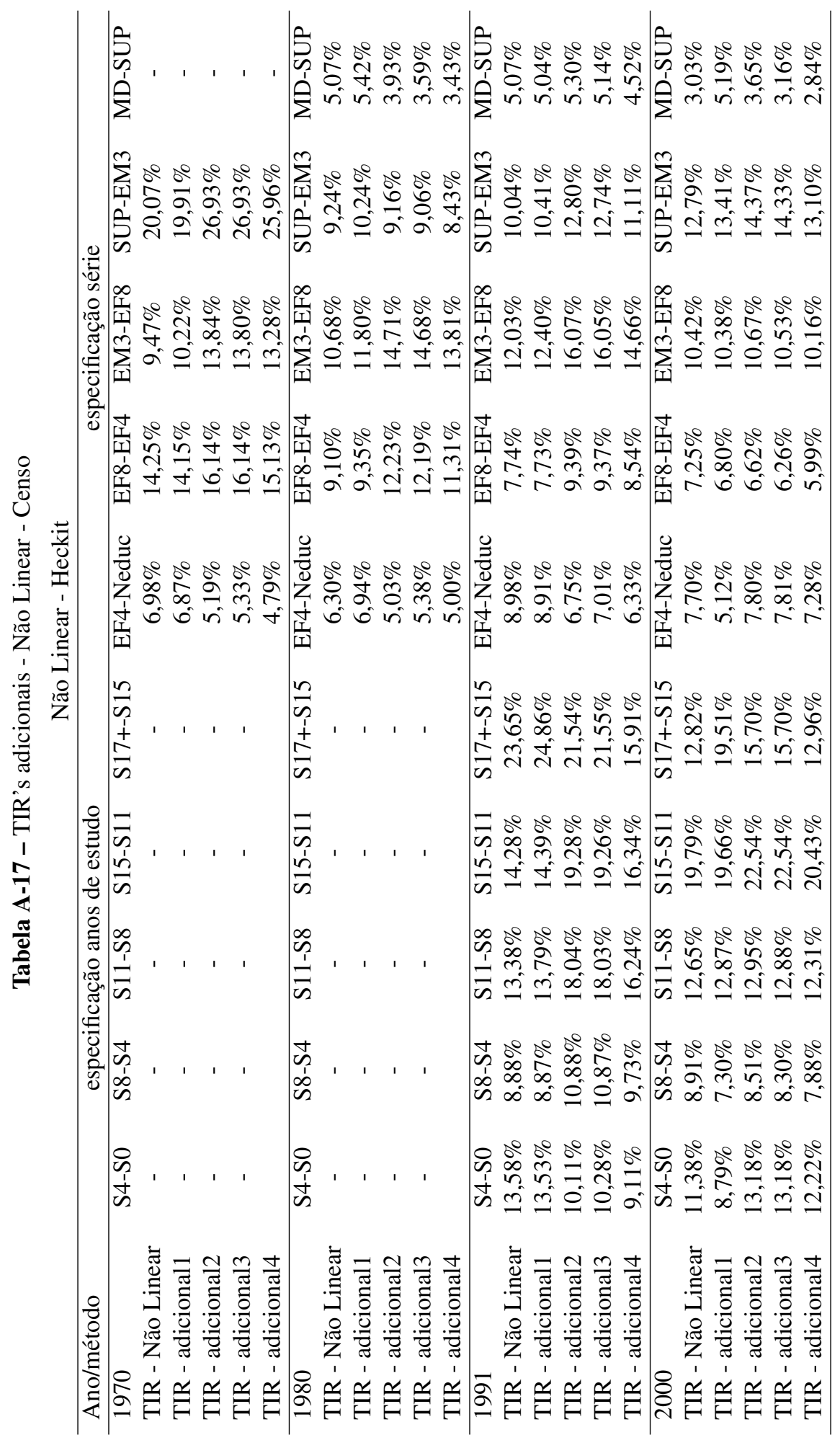


Tabela A-18 - Custos anuais por nível escolar (POF-PNAD) e \% da renda (POF)

\begin{tabular}{lcccccc}
\hline POF & PRE & PRI & GIN & SEC & SUP & MD \\
1996 & 1236,14 & 2051,73 & 2051,73 & 2578,34 & 3837,34 & 5226,79 \\
\% da renda & $5,68 \%$ & $7,24 \%$ & $7,24 \%$ & $7,88 \%$ & $13,25 \%$ & $15,32 \%$ \\
\hline PNAD & PRE & PRI & GIN & SEC & SUP & MD \\
1992 & 858,21 & 867,87 & 931,51 & 1127,13 & 3092,51 & 4606,65 \\
1993 & 913,33 & 840,75 & 908,31 & 1065,66 & 3192,33 & 5087,81 \\
1995 & 1073,88 & 1085,60 & 1205,78 & 1455,22 & 4497,32 & 7280,47 \\
1996 & 1211,30 & 1012,8 & 1289,02 & 1476,46 & 4390,21 & 8096,80 \\
1997 & 1188,49 & 1019,1 & 1108,29 & 1462,84 & 3939,46 & 7288,00 \\
1998 & 1101,25 & 1046,87 & 1068,51 & 1356,19 & 4107,70 & 7676,79 \\
1999 & 1094,67 & 938,23 & 1037 & 1148,24 & 4112,12 & 8564,41 \\
2001 & 935,36 & 917,38 & 925,29 & 1073,03 & 3746,03 & 7861,76 \\
2002 & 878,45 & 871,72 & 925,25 & 1063,20 & 3697,14 & 7281,24 \\
2003 & 810,52 & 853,05 & 777,2 & 888,04 & 2938,66 & 6199,65 \\
2004 & 800,71 & 848,14 & 828,96 & 879,97 & 3174,58 & 5087,52 \\
\hline Censo & PRE & PRI & GIN & SEC & SUP & MD \\
1970 & - & 1140,43 & 1140,43 & 1433,26 & 2131,31 & - \\
1980 & 493,38 & 611,88 & 668,10 & 864,44 & 1797,81 & 1741,82 \\
1991 & 452,18 & 474,95 & 530,07 & 674,73 & 1798,97 & 3263,08 \\
2000 & 469,68 & 464,02 & 488,56 & 617,61 & 2050,59 & 3885,65 \\
\hline
\end{tabular}

Figura A-1 - Perfis da renda-experiência - Censo - especificação anos de estudo
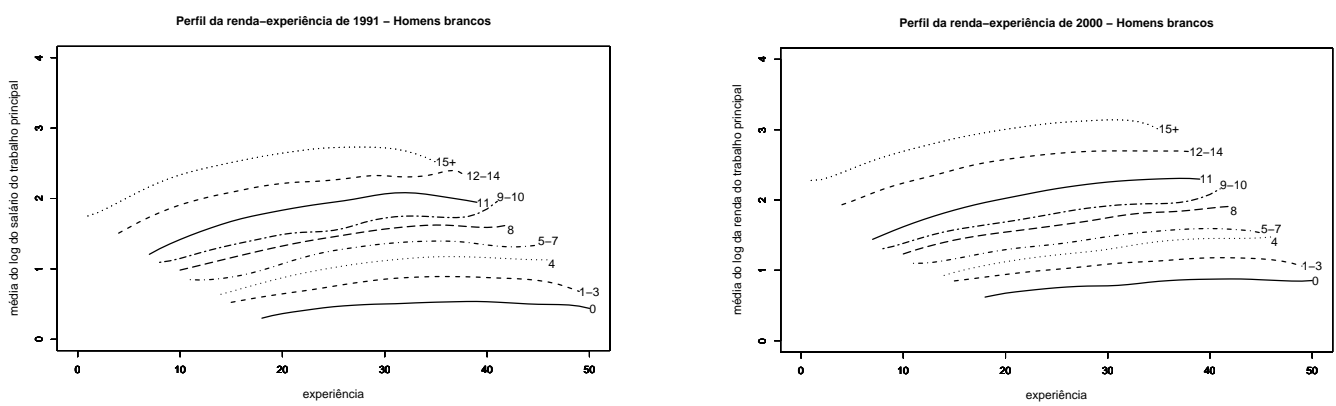
Figura A-2 - Perfis da renda-experiência - PNADs - especificação anos de estudo
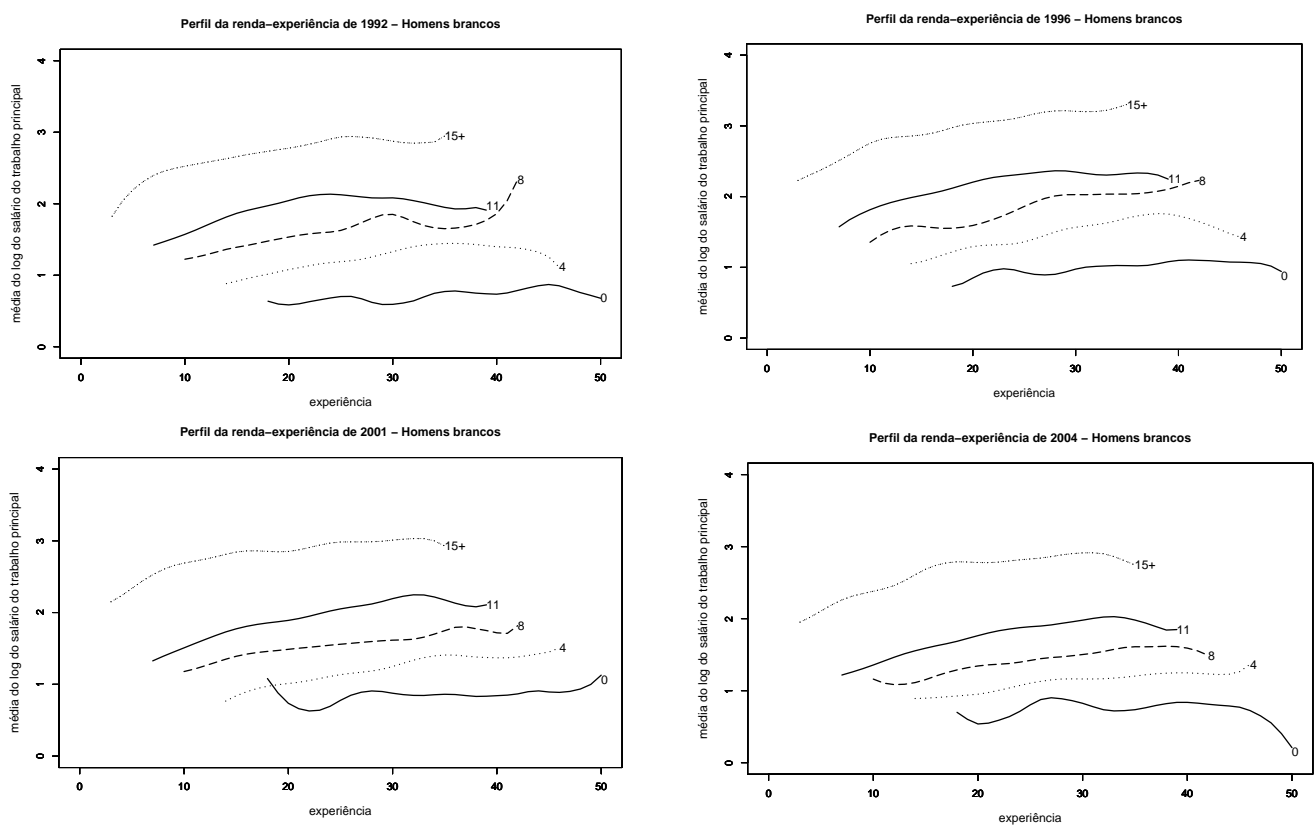

Figura A-3 - Perfis da renda-experiência - Censo - especificação série
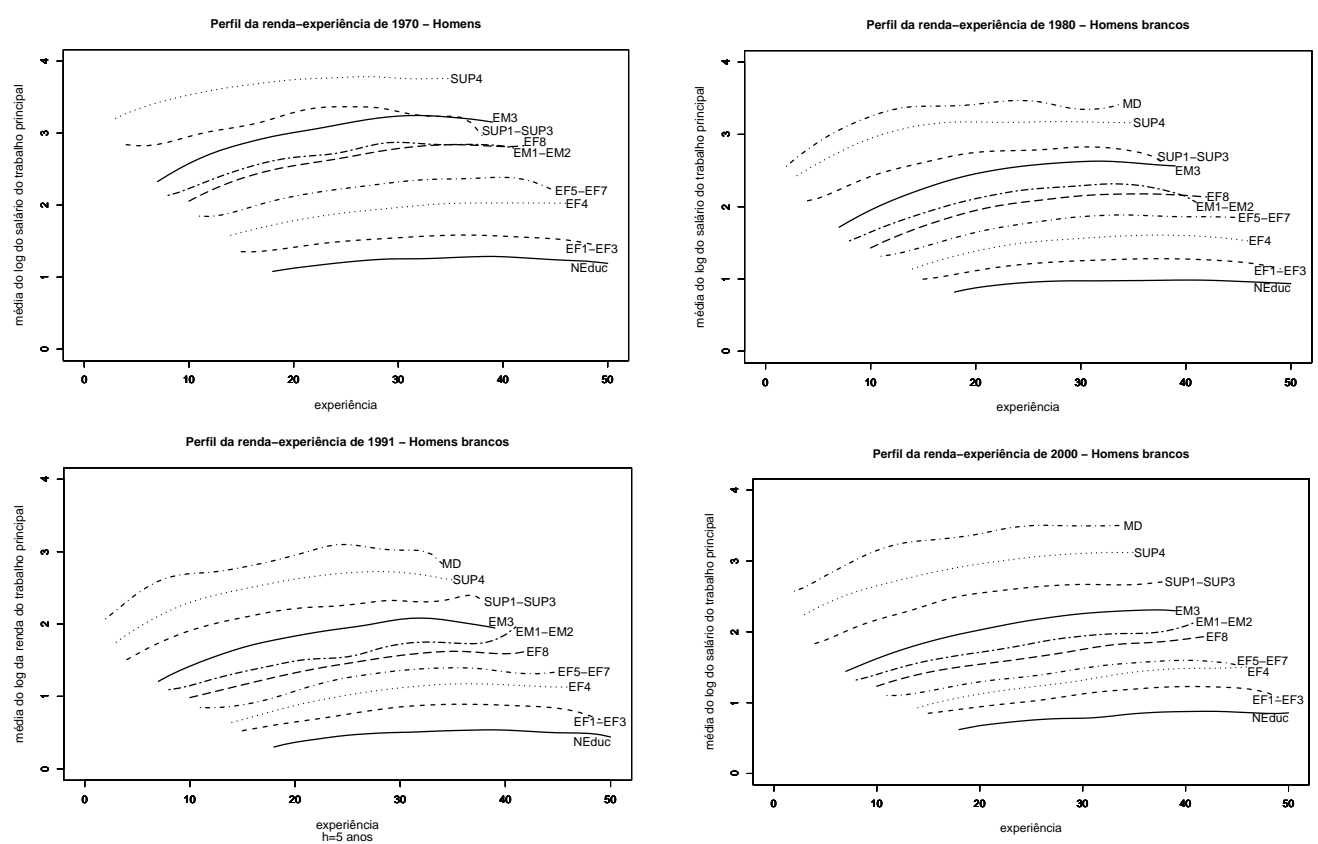
Figura A-4 - Perfis da renda-experiência - PNAD - especificação série
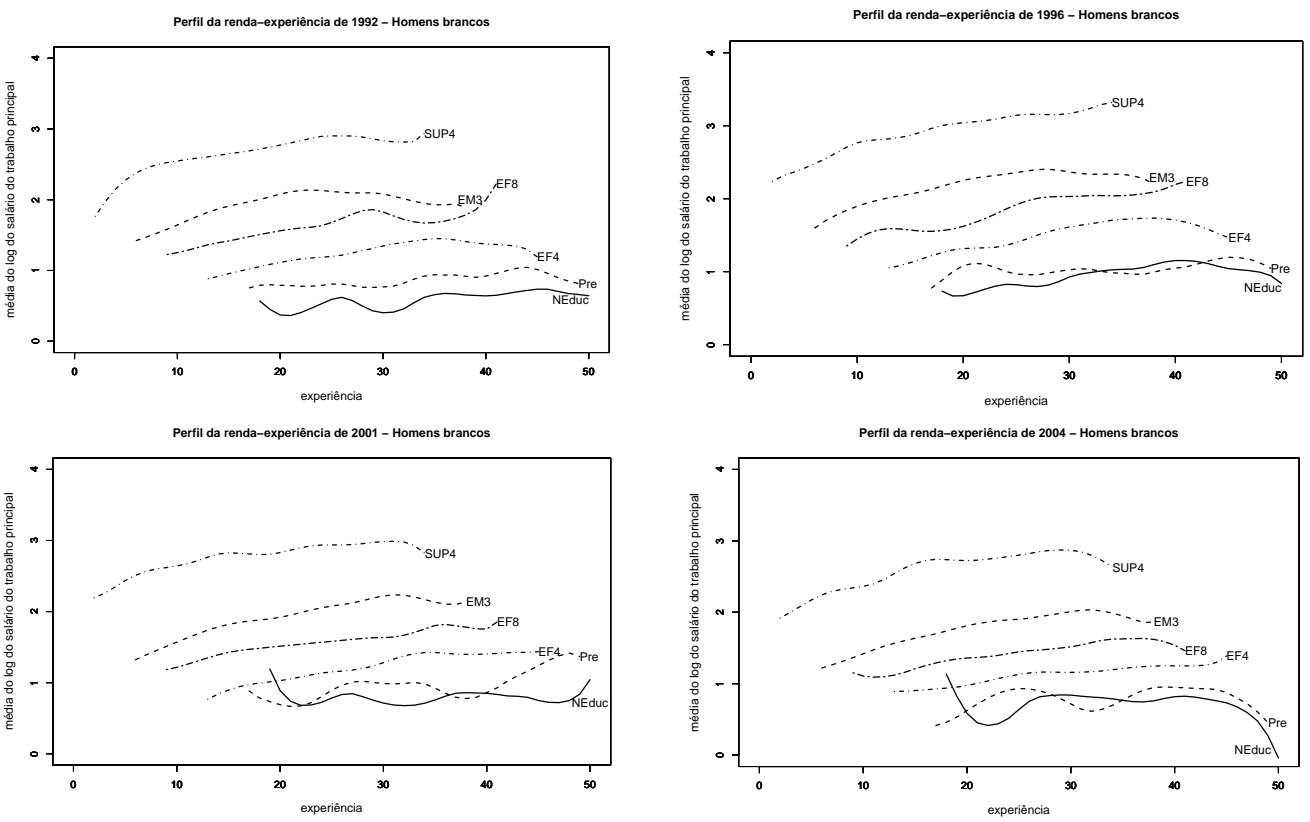

Figura A-5 - Evolução temporal das TIR's - PNAD e Censo
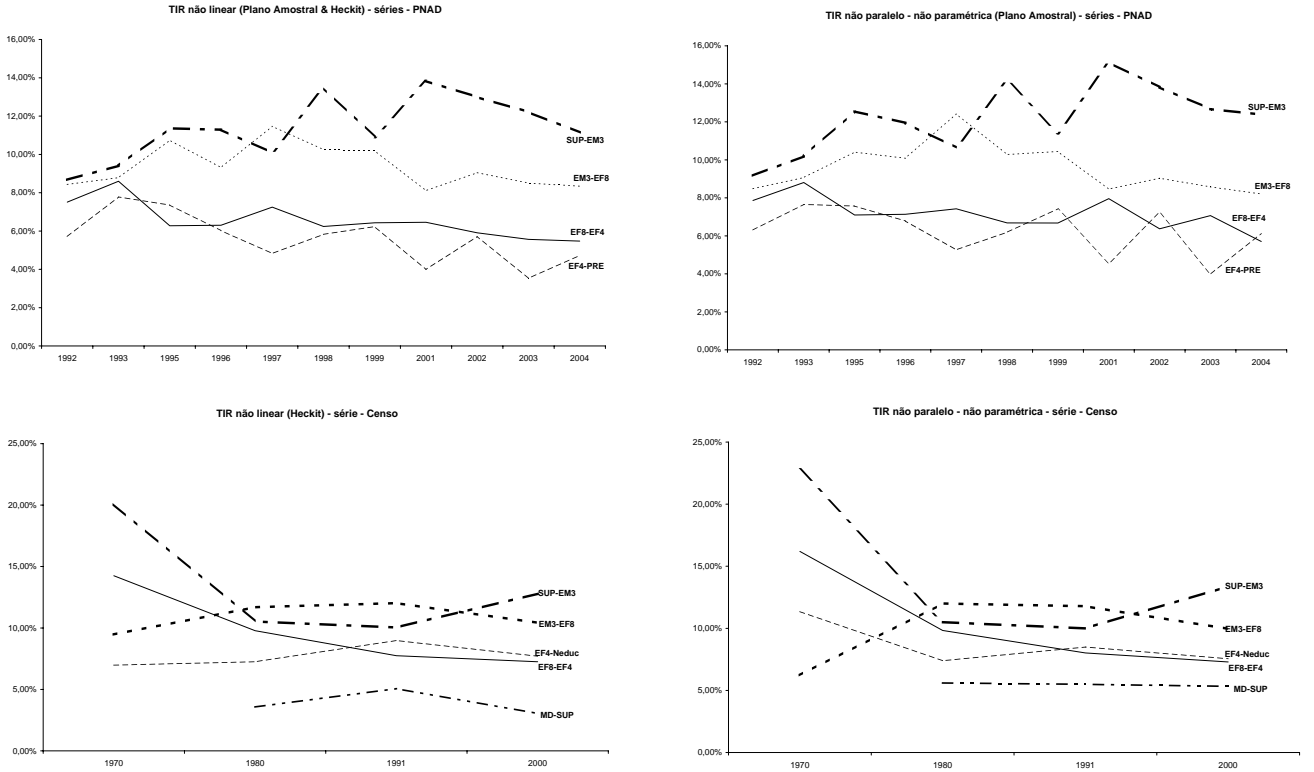
Figura A-6 - Evolução temporal das TIR's adicionais - PNAD e Censo
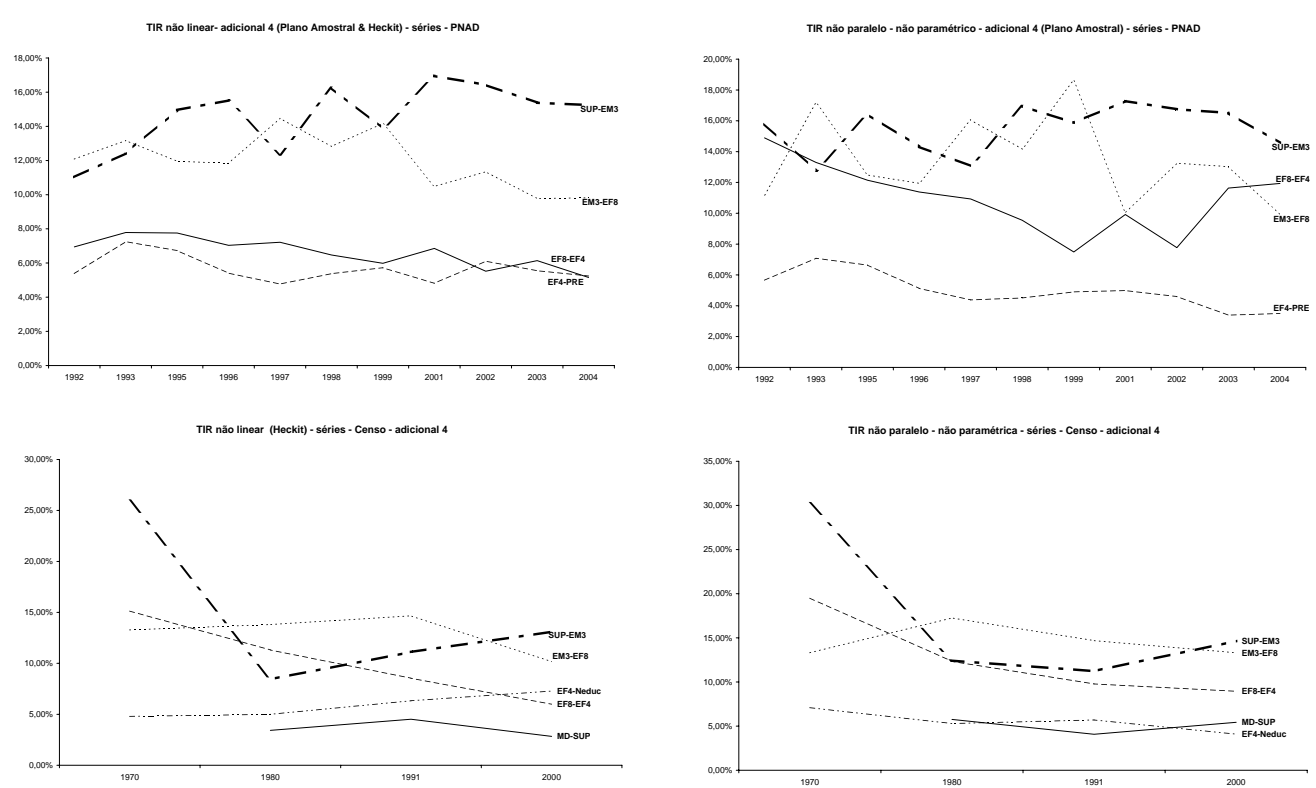